\title{
Ley y negociación colectiva en la determinación del tiempo de trabajo del personal que presta servicios esenciales de protección civil en la Comunidad Autónoma Vasca*
}

Edurne Terradillos Ormaetxea

DOI: https://doi.org/10.47623/ivap-rvap.108.2017.07

\begin{abstract}
Sumario: I. Introducción.-II. La regulación jurídica de los servicios de protección civil.-III. El marco de la regulación, legal y negocial, de la jornada y los descansos del personal que presta servicios de protección civil. III.1. El marco jurídico-legal o la situación de anomia. III.2. Algunos modelos de regulación convencional del tiempo de trabajo del personal de protección civil de la Comunidad Autónoma Vasca.-IV. La normativa jurídico-laboral. Posible marco de referencia.-V. La Directiva 2003/88/CE sobre aspectos de la ordenación del tiempo de trabajo y su transposición al ordenamiento español V.1. Aplicación de la Directiva al ámbito del sector público. V.2. Distinción entre tiempo de trabajo y tiempo de descanso a la luz de la Directiva y de su jurisprudencia. V.3. Las disposiciones de la Directiva que permiten exceptuar la aplicación de algunos de sus contenidos en un Estado miembro. V.4. Tiempo de trabajo nocturno. V.4.1. Los instrumentos jurídicos añadidos que sirven para articular excepciones a las disposiciones sobre trabajo nocturno. -VI. Conclusiones.
\end{abstract}

\section{Introducción}

El factor tiempo aplicado a la jornada laboral resulta especialmente sensible a los cambios económico-sociales y a sus repercusiones jurídicas. En etapas de expansión económica, por ejemplo, se tiende a recurrir a los contratos de duración indefinida e, incluso, la apropiación del tiempo de trabajo del trabajador se prolonga a través del mecanismo de las horas extraordinarias. Utilizando un símil agrario, esas épocas se ha definido como "cultivo extensivo». En periodos de crisis o de recesión

\footnotetext{
* Este trabajo se enmarca en el Proyecto de Investigación MINECO FEDER DER2014-52549-C4-3-R.
} 
económica, la clase empresarial opta por la precarización y los contratos temporales; así como reclaman menos legislación restrictiva de la denominada "flexibilidad externa" (despido). En el ámbito de la conocida como "flexibilidad interna" (modificación sustancial de las condiciones de trabajo, reducción de jornada...) los intereses empresariales reclamarán también la mayor flexibilidad posible para adaptarse a las fluctuaciones del mercado de trabajo. Este periodo ha sido a su vez comparado a un "cultivo intensivo"(1).

Sin que creamos que sea procedente realizar ahora una retrospectiva de los hitos del Derecho obrero, en primer lugar, y del Derecho del Trabajo, después, en ese recorrido de alcanzar la jornada laboral de ocho horas(2), es un lugar común que los abusos del Estado liberal provocaron una movilización-concienciación social tal (luddismo, maquinismo...) que el Estado decidió intervenir en la determinación de la duración máxima de la jornada laboral. En España, "la llave maestra» que permitió que podamos empezar a hablar de Derecho obrero fue la conocida como "Ley Benot", de 24 de julio de 1873, sobre "regularización del trabajo en los talleres y la instrucción en las escuelas de los niños obreros de ambos sexos" (3). Aunque el objeto de la ley se enfocara más a la reducción de la jornada de los niños en pos de su más prolongada escolarización (4), que a la minoración del tiempo de trabajo por antonomasia, esta ley se enmarca en las primeras medidas de nuestro entorno europeo encauzadas a limitar el trabajo de las mujeres y de los niños, que irían extendiéndose progresivamente al conjunto de todos los obreros, $y$, por ende, a los funcionarios/as.

La limitación de las horas de trabajo fue gradual hasta la aplicación del principio de la jornada de ocho horas o de la semana de cuarenta y ocho horas que, por ejemplo, constituyó el primer orden del día de la reunión de la Conferencia Internacional del Trabajo (OIT), celebrado en Washington entre octubre y noviembre de 1919. En su seno se adoptaron seis

(1) ALARCÓN CARACUEL, Manuel Ramón: La ordenación del tiempo de trabajo, Madrid, Tecnos, 1988 , p. 25.

(2) Para la perspectiva histórica, cfr. ESPUNY ITOMÁS, M.J.: «La Jornada laboral: perspectiva histórica y valoración jurídica», en Trabajo: Revista andaluza de relaciones laborales, n. ${ }^{\circ} 13,2004$, pp. 115 y 22.

(3) PALOMEQUE LÓPEZ, M.C. y ÁlVAREZ DE LA ROSA, M.: Derecho delTrabajo, 22. ${ }^{\circ}$ edición, Ed. Universitaria Ramón Areces, 2014, p. 58.

(4) El propio Benot, al presentar su proyecto de ley, resumió estos argumentos con las siguientes palabras: "En la gran sociedad humana todos ganan con la ganancia de cada uno y todos pierden con la deficiencia de una sola clase cualquiera de la sociedad. Cualquier negación de derechos es una especie de suicidio, porque en toda destrucción pierde la sociedad el usufructo de lo que hubieran producido las fuerzas destruidas, y, por el contrario, toda mejora es un aumento de las fuerzas sociales y, por consiguiente, del bienestar común". Diario de sesiones, 24 de julio de 1873. 
convenios y seis recomendaciones, incluyendo el Convenio $n .^{\circ} 1$ sobre la duración de la jornada de trabajo (5).

La adopción general de la jornada de ocho horas desencadenó en los primeros años del siglo pasado un conjunto de opiniones favorables o desfavorables, a partes iguales, sobre sus consecuencias, en tanto que se trataba de determinar los resultados económicos de las empresas y los efectos personales sobre los obreros.

Entonces el ideal de la jornada de trabajo fijada en ese máximo de las ocho horas se sostenía por varias razones: si las jornadas laborales son excesivamente prolongadas, provocan que el trabajo prestado pierda calidad, y por tanto, también la obra producida, creciendo sus taras, mermas y defectos. La reducción de la jornada de trabajo coincide con un aumento de producción por hora y aunque puede verse favorecido por el perfeccionamiento de algunas máquinas, los resultados se obtienen por la mayor agilidad de los agentes que intervienen en la producción: los trabajadores aportan todas las mañanas una mayor carga de energía exista o no una prima a la producción y trabajan mejor y de una manera más responsable.

En efecto, tanto estudios de principio del siglo pasado como actuales(6) demuestran que los accidentes de trabajo son más frecuentes y graves cuando las jornadas son alargadas porque la fatiga disminuye la atención y la rapidez de los movimientos, multiplicando las posibilidades de daño. Cuando la jornada diaria supera las 7, 8 u 9 horas, la media de riesgo de accidente aumenta exponencialmente, sin perjuicio de que haya factores añadidos (el tipo de accidente y, quizás, el tipo de trabajo, pero también los tiempos de descanso) que contribuyan a reducir o incrementar esa media. Pero parece claro que el riesgo de accidente puede doblarse si la jornada (de 8 horas) se eleva a las 12 horas. Y lo mismo puede indicarse respecto de las jornadas computadas semanalmente. $Y$ así, mientras que está demostrado que la exposición a jornadas muy extensas tiene un efecto directo y a corto plazo sobre los accidentes de trabajo, otros estudios demuestran empíricamente que unas jornadas muy largas repercuten directa y negativamente (relación lineal) sobre la salud, ahora a medio o a largo plazo; sin perjuicio de que factores diversos, como el tipo de trabajo, ejerzan cierta influencia en el resultado final. Y, precisamente, el tipo de servicio objeto de este estudio, el del personal de pro-

(5) http://www.ilo.org/wcmsp5/groups/public/---dgreports/---dcomm/---webdev/documents/publication/wcms_082363.pdf

(6) Deloitte Consulting CVBA/SCRL European Commission DG for Employment, Social Affairs and Equal Opportunities Study to support an Impact Assessment on further action at European level regarding Directive 2003/88/EC and the evolution of working time organization. Final report. 21 December 2010 , pp. 33 y ss. 
tección civil, requiere de unas condiciones físicas y psíquicas más exigentes que otros trabajos.

Pero no sólo deben computarse esos efectos directos sobre la salud sino que a éstos terminarán por añadirse los efectos indirectos de las jornadas prolongadas, entre los cuales sobresalen la reducción de la calidad de vida o la adopción de comportamientos contraproducentes (consumo de café, alcohol, tabaco, falta de ejercicio).

A lo largo de la historia fueron distintas las razones que se impusieron en el apoyo de la reducción de la jornada. Se "descubrió» entonces la fórmula de distribución del día obrero proclamando la regla de «ocho horas para el trabajo, ocho para el descanso, ocho para la cultura e instrucción»(7). Efectivamente, empezaron a aparecer estudios que demostraban la necesidad de que el trabajador/a dispusiese de horas libres para el desarrollo de su propia personalidad. Los detractores de las jornadas reducidas ponían de relieve los peligros asociados al ocio del trabajo, peligros que bien se cebaban sobre la propia salud del trabajador, bien sobre la productividad de la empresa al acortarse las horas de trabajo (8). Actualmente, no existen muchos estudios que investiguen esa relación entre "jornadas alargadas y tiempo de ocio reducido o nulo", y, sin duda alguna, es más abundante la bibliografía que concierne a la conciliación de la vida familiar y laboral. La mayor parte de los estudios demuestran que el aumento del número de horas de trabajo por semana, especialmente más allá de las 40 horas, perjudica claramente la vida familiar y/o el equilibrio entre vida y trabajo (9).

(7) $\mathrm{RAE}$, J.: La tournée de Huit heures. Théorie et étude comparée de ses applications et de leurs résultats économiques et sociaux, París, V. Giard \& E. Briére, 1900, traduit par F. STARK, pp. 42-89, valora las aplicaciones de la jornada de ocho horas en distintas industrias.

(8) BERNALDO DE QUIROS, C.: Derecho social, Madrid, Instituto Reus, 1932, pp.

85-86, citando Veinticinco años de legislación social de Álvaro NúÑEZ LÓPEZ en que este autor critica la jornada de ocho horas porque perjudica a la producción y en consecuencia el propio obrero que de ella vive y que también es nociva al obrero, porque «al dejarles libres algunas horas facilita el acceso a la taberna y a otros lugares de vicio que desgraciadamente, le atraen"; GALLART FOLCH, A.: Derecho español del trabajo, Barcelona, Labor, 1936, pp.240-269.

(9) Deloitte Consulting CVBA/SCRL European Commission DG for Employment, Social Affairs and Equal Opportunities Study to support an Impact Assessment on further action at European level regarding Directive 2003/88/EC and the evolution of working time organization. Final report. 21 December 2010, pp. 36. VARGAS PRADA, S.: "Resultados de una revisión sistemática sobre la influencia de las largas jornadas de trabajo en la salud de los trabajadores", Archivos de prevención de riesgos laborales, vol. 18, n. ${ }^{\circ} 1,2015, \mathrm{pp} .23-24$, una recensión del trabajo de Bannai A., Tamakoshi A., The association bet ween lon $g$ working hours and health: $A$ systematic review of epidemiological evidence, Scan d J Work Environ. 2014; 40( 1): 5-18. doi:10.5271/ sjweh.3388. En este trabajo se definió "largas jornadas de trabajo" como el tiempo de trabajo superior a 40 horas a la semana, u 8 horas por día. Debido a que estudios previos han sugerido que el trabajo por turnos es perjudicial para la salud, se excluyeron de esta revisión aquellos estudios donde se incluía trabajadores por turnos para evitar el efecto que esta variable podía tener en la asociación. 
No se han encontrado investigaciones que examinen los efectos de la jornada sobre los hijos/as cuyos padres trabajen durante largas jornadas de trabajo, aunque es bien conocido que niños con padres que trabajan a turnos tienen menos probabilidades de alcanzar la educación superior. Tampoco hay evidencias acerca de la relación entre jornadas de trabajo extensas y escasa participación en grupos de interés social como partidos políticos, sindicatos, consejos de comunidad, etc., aunque la posible relación inversa se presenta evidente y lógica (a más horas de trabajo, menor participación social) (10).

Con todo, nadie desconoce que hay profesiones que debido a los bienes que protegen requieren desarrollarse durante las 24 horas del día, por la necesidad de garantizar la continuidad del servicio. Nos estamos refiriendo a los servicios de protección civil.

El estudio que sigue a continuación empleará la siguiente metodología y sistemática. En primer lugar, se revisará la legislación administrativa respecto del régimen jurídico aplicable a cierto personal funcionario y titular de los servicios de protección civil en materia de tiempo de trabajo, tanto la legislación específica como la general. Los servicios de protección civil que vamos a analizar y las especificidades del régimen estatutario de sus miembros es una materia para cuya regulación resulta habilitada la Comunidad Autónoma en virtud de títulos tales como el régimen local y la regulación del régimen estatutario de los funcionarios/as (art. 149.1.18); aunque siempre actuará con respeto a la legislación básica estatal. Por este último motivo, también se recurrirá al Estatuto Autónomo del Empleado Público, ley básica de ámbito estatal; y a su desarroIlo en esta Comunidad Autónoma, la Ley de Empleo Público Vasco, todavía en estado de Anteproyecto. Finalmente, se revisará la legislación laboral por actuar de referencia de la regulación de las condiciones de trabajo de los empleados públicos, desde luego de los laborales (véase el art. 51 del Estatuto Autónomo del Empleado Público Real Decreto Legislativo 5/2015, de 30 de octubre, por el que se aprueba el texto refundido de la Ley del Estatuto Básico del Empleado Público -EBEP-(11), sin perjuicio de que la redacción actual, al combinar la regulación específica del EBEP con la remisión a la legislación laboral ha dado como resultado un régimen complejo de ordenación en el que «tendríamos que ir acumu-

(10) Véase UGT : http://www.ugt.es/SitePages/NoticiaDetalle.aspx?idElemento=855

(11) Su texto prevé que «Para el régimen de jornada de trabajo, permisos y vacaciones del personal laboral se estará a lo establecido en este capítulo y en la legislación laboral correspondiente». La doctrina ha criticado la confusa redacción de este precepto, cfr. SALA FRANCO, T:: «EI personal laboral. La relación laboral especial de empleo público", en SÁNCHEZ MORÓN, M. (dir.): Comentarios a la Ley del Estatuto Básico del Empleado Público», ed. Lex Nova, 2007, pág. 128; GIL PLANA, J.: «EI tiempo de trabajo del empleado publico laboral», Revista del Ministerio de Trabajo e Inmigración, núm. 93, 2011, p. 235-236. 
lando y aunando las ventajas propias del régimen laboral y funcionarial en materia de tiempo de trabajo»(12). La Directiva 2003/88/CE ocupará también un lugar destacado en este estudio. Asimismo habremos de recurrir a los Acuerdos de las condiciones de trabajo de los colectivos que se analizan en este trabajo, por resultar legislación obligada. La jurisprudencia, estatal como de la UE, así como la doctrina científica especializada en esta materia abundarán en las conclusiones que se alcancen.

\section{La regulación jurídica de los servicios de protección civil}

Conforme al art. 1 de la Ley 17/2015, de 9 de julio, del Sistema de Protección Civil, "la protección civil, como instrumento de la política de seguridad pública, es el servicio público que protege a las personas y bienes garantizando una respuesta adecuada ante los distintos tipos de emergencias y catástrofes originadas por causas naturales o derivadas de la acción humana, sea ésta accidental o intencionada». La Ley 15/2012, de 28 de diciembre de Ordenación del Sistema de Seguridad Pública de Euskadi, describe las situaciones de emergencia, contemplando su art. 58.2 que «El sistema vasco de atención de emergencias y protección civil comprende el conjunto de acciones dirigidas a evitar, reducir o corregir los daños a personas y bienes y el patrimonio colectivo por toda clase de peligros o amenazas de origen natural, tecnológico o antrópico, cuando la amplitud o gravedad de sus efectos potenciales o efectivos impliquen una afectación colectiva grave, catástrofe o calamidad pública, así como en otros casos de urgencias o emergencias que puedan derivar en aquellas o pudieran requerir de la coordinación de distintos servicios y operativos", incluyéndose en los anteriores los fenómenos meteorológicos.

Más adelante, el art. 60.2 de la Ley $15 / 2012$ se pronuncia en torno a qué considerar servicios esenciales o básicos del sistema vasco de atención de emergencias y protección civil: «aquellos prestados por una administración, de forma directa o indirecta, cuya concurrencia es necesaria en las situaciones de emergencia, dada su disponibilidad permanente, carácter pluridisciplinar o especialidad, tales como los siguientes:

a) Los servicios de la red de alerta, incluido el Servicio Vasco de Meteorología.

b) El Centro de Coordinación de Emergencias de Euskadi.

c) El Servicio de Intervención Coordinadora.

d) Los servicios de prevención, extinción de incendios y salvamento.

(12) LÓPEZ AHUMADA, J.E.: «Regulación del tiempo de trabajo», en CARDENAL CARRO, M. (dir.): El personal laboral al servicio de las Corporaciones Locales", ed. La Ley, Madrid, 2010, pág. 536. 
e) Las fuerzas y cuerpos de seguridad.

f) Los servicios de asistencia sanitaria en emergencias.

g) Los servicios de lucha contra incendios forestales.

h) Los servicios de socorro, rescate y salvamento.

Su apartado 3 también señala cuáles serán los «servicios complementarios", esto es los que perteneciendo a administraciones, organizaciones o agrupaciones profesionales o voluntarias, públicas o privadas, se movilizan para concurrir en las emergencias, complementando la intervención de los servicios esenciales, tales como los siguientes:

a) El voluntariado de protección civil.

b) Las organizaciones técnicas y profesionales en materia de seguridad que, estando en posesión de cualquier tipo de acreditación para actuar en alguno de los ámbitos reglamentarios de seguridad, prestan colaboración voluntariamente o por requerimiento de las administraciones públicas.

c) Los bomberos de empresa.

d) Los servicios de las administraciones públicas no clasificados como esenciales o básicos al sistema, tales como los servicios de mantenimiento de carreteras y obras públicas y la red de albergues y servicios sociales.

e) Las empresas públicas o privadas, cuando por la naturaleza de su actividad se consideren necesarias para la prestación de asistencia ciudadana. Se consideran incluidos los servicios de suministro, mantenimiento y conservación de redes de telecomunicaciones, agua, gas y electricidad.

f) Otros medios auxiliares.

Este trabajo no pretende agotar el estudio del tiempo de trabajo de todos los colectivos ínsitos en la noción de servicio esencial o básico de protección civil. Al contrario, nos referiremos a tres profesiones que se han escogido por ser lo suficientemente distintas entre sí como para poder extraer conclusiones lo más completas posibles; y por desempeñarse durante el día y la noche. Este estudio se proyectará, entonces, sobre tres servicios: d) Los servicios de prevención, extinción de incendios y salvamento; e) Las fuerzas y cuerpos de seguridad; f) Los servicios de asistencia sanitaria en emergencias.

Por ir centrándonos en los servicios esenciales de protección civil a los que se dedica este trabajo, el art. 3 del Anteproyecto de Ley reguladora de los servicios de prevención y extinción de incendios y salvamento de Euskadi 2015(13), intitulado "Naturaleza y funciones" retrata aquéllos

(13) https://www.irekia.euskadi.eus/uploads/attachments/5435/Anteproyecto_de_Ley.pdf?1415968247 
como "uno de los servicios esenciales o básicos del sistema vasco de atención de emergencias y protección civil de conformidad con lo dispuesto en el artículo 60.2 de la Ley 15/2012, de 28 de junio, de Ordenación del Sistema de Seguridad Pública de Euskadi».

Sin embargo, el Capítulo III del citado Anteproyecto que se destina al régimen estatuario del personal dedicado a la prestación de esos servicios, no prevé nada respecto del tiempo de trabajo de este personal, por lo que se intuye ya la importante función que los instrumentos negociadores cumplen en este campo.

\section{El marco de la regulación, legal y negocial, de la jornada y los descansos del personal que presta servicios de protección civil}

\section{III.1. El marco jurídico-legal o la situación de anomia}

En el recorrido por el análisis legal, sirva, en primer lugar, acudir a la Constitución Española (CE). El artículo 40.2 de la Norma Fundamental proclama que "los poderes públicos [...] garantizarán el descanso necesario, mediante la limitación de la jornada laboral».

La doctrina científica subraya que el aspecto más clásico de la regulación del tiempo de trabajo como mecanismo de protección físico-psíquica, de protección de la salud del trabajador/a es la que parece recogerse también en la Constitución española (14). Y, efectivamente, de acuerdo con el diccionario de la Real Academia de la Lengua Española, la segunda acepción del sustantivo "jornada" responde a "tiempo de duración del trabajo diario" y parece que no podría aceptarse que el descanso viniera después del transcurso de 24 horas ya que entonces no se traduciría en una limitación de la jornada -obviamente porque un día tiene 24 horas - sino que se trataría de un descanso "tras un período de 24 horas".

Pero el derecho ínsito en el art. 40 CE requiere ser desarrollado en el ámbito administrativo (véase el art. 53.3 CE) para poder convertirse en derecho alegable. Por eso debemos acudir al marco jurídico-administrativo actual. En la Ley 6/1989, de 6 de julio, de la Función Pública Vasca art. 73.1 (h), se contempla como deber de los funcionarios el cumplir estrictamente la jornada y el horario de trabajo establecido. Por su parte, el artículo 47 del EBEP, titulado «Jornada de trabajo de los funcionarios pú-

(14) Cfr. MORENO VIDA, M.N.: "Configuración general del tiempo de trabajo: algunas reflexiones críticas", en PERÁN QUESADA, S. (dir. y coord.,): La ordenación del tiempo de trabajo en el siglo XXI. Retos, oportunidades y riesgos emergentes, Ed. Comares, 2014, p. 38 y ss.; autora que contrasta ese objetivo con otros más presentes a partir de la segunda mitad de los años 90: la conciliación de la vida familiar, personal y laboral, y el reparto del empleo. 
blicos", anuncia que "Las Administraciones Públicas establecerán la jornada general y las especiales de trabajo de sus funcionarios públicos». Y poco más recoge sobre la jornada, al margen de permitir que sea a tiempo completo o a tiempo parcial.

Continuando por la senda de la revisión de la legislación específica, sin embargo, no se halla ninguna regulación concreta relativa a la posible jornada especial del personal dedicado a la protección civil; menos aún se halla alguna relativa a los servicios básicos. Además, aunque del art. 47 EBEP pudiera parecer que la Administración Pública goza de total libertad para determinar la jornada de trabajo, debe tenerse presente que esta condición de trabajo está comprendida entre las materias sujetas a negociación previa con los representantes de los trabajadores de conformidad con lo previsto en el artículo 37.1.m) del EBEP; materia que tendrá «el margen que abren las leyes aplicables, entre ellas, los artículos 47 a 50 EBEP, en la medida en que las normas legales aplicables establezcan derechos con carácter de mínimos, lo que no siempre ocurre» (15). Para cierta doctrina científica(16), las Administraciones Públicas deberían afrontar la negociación de estas materias, teniendo en cuenta las exigencias de la productividad y la calidad de los servicios.

No obstante, dado que el art. 47 del EBEP habla de la posibilidad de fijar jornadas especiales sin ligar dicha posibilidad a norma alguna, la doctrina ha admitido en relación con los empleados públicos laborales que debe aceptarse, junto a la norma laboral en materia de jornadas especiales, que la Administración Pública pueda fijar, previa negociación colectiva, jornadas especiales frente a la jornada ordinaria instituida(17). En este trabajo se opina que lo mismo puede predicarse respecto de las jornadas especiales de los funcionarios públicos; incluso con más argumentos ya que el art. 47 se titula «Jornada de trabajo de los funcionarios públicos".

Finalmente, la Disposición Adicional Decimoctava de la Ley de la Función Pública Vasca(18) insiste en el patrón de «jornada» al referirse a ciertas medidas de reparto y reordenación del tiempo de trabajo.

(15) SÁNCHEZ MORÓN, M.: Derecho de la Función Pública, Tecnos, 2013, Séptima Edición, p. 279280.

(16) De nuevo, SÁNCHEZ MORÓN, M.: Derecho de la Función Pública..., op. cit., p. 280.

(17) GIL PLANA, J.: «El tiempo de trabajo...», op. cit., p. 240. El autor observa de que esa posibilidad que se ve refrendada en la práctica negocial, tanto anterior o posterior al EBEP, en la que se contemplan distintas formulaciones de jornadas especiales.

(18) «Al objeto de posibilitar medidas de reparto y de reordenación del tiempo de trabajo, las Administraciones Públicas vascas podrán conceder al personal incluido en el ámbito de aplicación de la presente ley la reducción de su jornada de trabajo con la correspondiente minoración de retribuciones, siempre que las necesidades del servicio y la planificación de los recursos humanos lo permitan y dentro de los límites presupuestarios de cada Administración». La cursiva es nuestra. 
Por su parte, el Anteproyecto de Ley sobre el Empleo Público Vasco cuyo ámbito de aplicación abarcará a los servicios de protección civil en el caso de que se apruebe (art. 4) (19) desarrolla algo más el capítulo dedicado a la jornada, donde debe llamarse la atención sobre la definición de ese Servicio en el art. 169.1 y, por supuesto, sobre el patrón de «jornada» que utiliza, definiéndose ésta como el «tiempo durante el cual el personal empleado público debe permanecer en el trabajo a disposición de la entidad correspondiente y en el ejercicio de su actividad y de sus funciones". Adviértase que la norma administrativa rehúsa referirse al "centro de trabajo" y opta por un concepto más amplio como es "estar a disposición»; en una elección muy próxima a la referencia a permanecer «en el ámbito de organización del empleador" que contiene el art. 1.1 ET.

De manera similar a como lo hace el EBEP se pronuncia este Anteproyecto en relación con el establecimiento de la jornada general y las especiales de trabajo, es decir, realizando una remisión completa a la negociación colectiva. Por medio de este instrumento colectivo se determinará también la duración de la jornada y su distribución a lo largo del año. Una vez efectuada esa llamada de actuación a la autonomía colectiva, el Anteproyecto de Ley prevé una limitación «incompleta» de la jornada a través del tiempo de descanso, ya que sólo hace alusión al descanso de vacaciones y a los permisos por asuntos particulares en el art. 169.2(20).

Yendo a la legislación especial de cada uno de estos colectivos, en el caso del personal estatutario del Servicio Vasco de Salud-Osakidetza, encuadrados sus servicios de urgencia dentro de la protección civil (art. 60.2 Ley 15/2012, citada), su legislación general (Ley 8/1997, de Ordenación Sanitaria de Euskadi), a pesar de regular condiciones de trabajo como la determinación del salario o el procedimiento de clasificación profesional como "normas comunes" a desarrollar en los respectivos estatutos de cada personal (art. 28), tampoco se ocupa del tiempo de trabajo. Su art. 28 recoge un tibia referencia a los «derechos de remuneración que corresponda, descanso necesario, no discriminación, sindicación, huelga y participación en la determinación de las condiciones de trabajo». Ahora bien, conviene subrayar que la Ley 8/1997 apela al «descanso necesario», única alusión al tiempo de trabajo que

(19) Su texto prevé que «El personal de los servicios de prevención y extinción de incendios y de salvamento se regirá por la presente Ley, sin perjuicio de las peculiaridades que se establecen en su legislación específica».

(20) "Las Administraciones Públicas vascas establecerán la jornada general y las especiales de trabajo de su personal, previa negociación colectiva al efecto. La jornada de trabajo fijará su duración total anual y la

distribución de la misma. En todo caso, esta distribución deberá garantizar el tiempo de descanso correspondiente a vacaciones y a permisos por asuntos particulares que corresponda al personal empleado público". 
efectúa esta ley, quizás por ser más importante para ese colectivo que la determinación del módulo de la jornada.

También es oportuno traer a colación el caso del personal de $\mathrm{la} \mathrm{Er}$ tzaintza-Policía vasca, en cuanto que se trata de personal que presta un servicio público de protección civil (art. 60.2 de la Ley 15/2012, citada). La Ley 4/1992, en su art. 77, después de efectuar una alusión general a la determinación de la duración y ordenación de la jornada de trabajo y el régimen de descansos (apdo. 1), permite que "En casos excepcionales, cuando existan razones de servicio que lo hagan necesario, los funcionarios podrán ser requeridos para el servicio fuera de su jornada de trabajo. Asimismo, y por las mismas razones, podrá imponerse la obligación de permanecer en las dependencias policiales o mantenerse en situación de disponibilidad" (apdo. 2) (21).

$\mathrm{Ni}$ la Ley 1/1996, de 3 de abril, de gestión de emergencias, ni el Anteproyecto de Ley reguladora de los servicios de prevención y extinción de incendios y salvamento de Euskadi 2015, como legislación específica, recogen nada que responda a esta duda que nos ocupa.

Por último, conviene hacer hincapié en la referencia que se hace en el EBEP a la legislación laboral aplicable en relación con el personal laboral (art. 169.4), volviendo a referirse a la «jornada» (22).

En definitiva, la legislación administrativa general y específica de los servicios de protección civil no contempla ninguna limitación específica de la jornada por medio del reposo diario ni tampoco determina cuál será el descanso diario, semanal, etc., de ese personal (excepción hecha de la referencias genéricas al "descanso necesario", etc.). No obstante, queda claro que la horma de la determinación de la prestación de trabajo en el ámbito administrativo es la "jornada», y no el "turno" o los "módulos».

Con todo, la descripción del marco normativo quedaría incompleto si no acudiéramos a la regulación convencional.

\section{III.2. Algunos modelos de regulación convencional del tiempo de trabajo del personal de protección civil de la Comunidad Autónoma Vasca}

Ante la escasa regulación del tiempo de trabajo por parte de la legislación jurídico-administrativa, es difícil responder a la cuestión de cuáles

(21) La cursiva es nuestra. Es el art. 103.3 de la Ley 4/1992 el que contempla la jornada como materia de negociación colectiva, si bien sujeta a lo negociado en la Mesa General de negociación constituida para la determinación de las condiciones de trabajo de los funcionarios de la Administración de la Comunidad Autónoma; de modo que la jornada máxima anual de trabajo regulada en este ámbito actuará de límite para el ámbito inferior de negociación.

(22) «La jornada del personal laboral se regirá por lo previsto en este artículo y por la legislación laboral que sea de aplicación». 
son los límites que la negociación colectiva se topa en este campo. Conforme al art. 38 del EBEP, y al amparo del reconocimiento de la negociación colectiva de los funcionarios que provee el art. 31 de esa ley, los representantes de las Administraciones Públicas podrán concertar Pactos y Acuerdos con la representación de las organizaciones sindicales legitimadas a tales efectos, para la determinación de condiciones de trabajo de los funcionarios de dichas Administraciones, tiempo de trabajo incluido (letra $\mathrm{m}$ ).

Sin embargo, dado el carácter de urgencia e inmediatez que plantea la prestación de esos servicios, debido a la naturaleza esencial de los bienes que protegen, podría plantearse la hipótesis de la necesidad de adecuar la prestación de estos servicios al interés elevado que prestan, yendo más allá -y no buscando precisamente la mayor favorabilidad del personal- del régimen legal establecido para el resto de los funcionarios y/o trabajadores; esto es, cabe preguntarse hasta qué punto la negociación colectiva puede "afectar" lo dispuesto -o no dispuesto- en la ley, ya sea a fin de prestar un servicio lo más eficaz posible dirigido a garantizar un bien tan esencial, ya sea a fin de combinar ese objetivo y el principio de "lex favoritatis", en cuanto a la posibilidad de que las partes elijan el Derecho aplicable. Incluso podría plantearse la hipótesis de forma más acabada: ies posible que los sujetos negociadores de un Acuerdo colectivo regido por la legislación administrativa creen Derecho "ad hoc»?

Acerquémonos, pues, a algunos ejemplos convencionales, conforme a la selección efectuada en la Introducción de este trabajo: los servicios de prevención, extinción de incendios y salvamento; las fuerzas y cuerpos de seguridad; y los servicios de asistencia sanitaria en emergencias. Las tres son actividades que pueden (y suelen) desenvolverse durante el día y la noche, de modo que se suelen articular turnos de trabajo entre su personal.

En el caso del personal de la Ertzaintza y del personal estatutario del Servicio Vasco de Salud-Osakidetza, el Decreto 12/2016, de 2 de febrero, por el que se establece la jornada de trabajo anual para el año 2016 para el personal funcionario, estatutario y laboral de la Administración Pública de la Comunidad Autónoma de Euskadi (23), incluye dentro de su ámbito de aplicación, al personal de la Ertzaintza y de Osakidetza-Servicio Público de salud (art. 1.1) (24). Por otra parte, la aprobación del Decreto 173/2013,

(23) BOPV de 8 febrero 2016.

(24) En cualquier caso debe recordarse que sigue vigente la Ley 2/2012, de 29 de junio, de Presupuestos Generales del Estado para el año 2012; ley que amplió la jornada general del trabajo en el Sector Público a 37 horas y media semanales de trabajo efectivo de promedio en cómputo anual. Véase la Disp. Adic. Septuagésima primera de la citada Ley que incluye en su ámbito de aplicación a «a) La Administración General del Estado, las Administraciones de las Comunidades Autónomas y las Entidades que integran la Administración Local». 
de 5 de marzo, por el que se establece la jornada anual, para el ejercicio 2013, del personal funcionario, estatutario y laboral de la Administración de la Comunidad Autónoma de Euskadi, entre los que se encuentra el personal de Osakidetza-Servicio vasco de salud, obligó a aprobar el Decreto 351/2013, de 21 de mayo, de modificación del Decreto por el que se aprueba el Acuerdo regulador de las condiciones de trabajo del personal de Osakidetza-Servicio vasco de salud, para los años 2007, 2008 y 2009 (BOPV 27 Mayo 2013); evidencias, todas, de la tendencia a la homogenización cuantitativa - que no cualitativa- de la jornada laboral en el ámbito de las Administraciones Públicas.

En el Acuerdo regulador de las condiciones de trabajo de Osakidetza se contempla la posibilidad de trabajar durante 24 horas seguidas, pero estos turnos se realizan únicamente como excepción y bajo ciertas condiciones. En efecto, el artículo $30 \mathrm{del}$ Acuerdo regulador de las condiciones de trabajo del personal de Osakidetza-Servicio vasco de salud, para los años 2007, 2008 y 2009 (25), titulado, Jornada y descansos diarios, prevé en su apartado 1 que «El tiempo de trabajo correspondiente a la jornada ordinaria(26) no excederá de doce horas ininterrumpidas. No obstante, mediante la programación funcional de las Organizaciones de servicios de Osakidetza se podrán establecer jornadas ordinarias de hasta veinticuatro horas para determinados servicios o unidades sanitarias, con carácter excepcional y cuando así lo aconsejen razones organizativas o asistenciales» (27). Ese mismo artículo contempla algunas excepciones al descanso inter-jornadas, descanso que «se reducirá, en los términos que exija la propia causa que lo justifica, en los siguientes supuestos:

a) En el caso de trabajo a turnos, cuando el personal cambie de equipo y no pueda disfrutar del período de descanso diario entre el final de la jornada de un equipo y el comienzo de la jornada siguiente.

b) Cuando se sucedan, en un intervalo inferior a doce horas, tiempos de trabajo correspondientes a jornada ordinaria y/o jornada complementaria» (28).

También es oportuno traer a colación el caso del personal de la Ertzaintza-Policía. Al regular la jornada y el tiempo de descanso, el Decreto 4/2012, de 17 de enero, por el que se aprueba el Acuerdo regulador de las

(25) BOPV de 27 de mayo 2013.

(26) En este trabajo no se abordará la naturaleza de las horas complementarias recogidas por el Acuerdo regulador citado. Su objeto es, por tanto, la jornada ordinaria.

(27) Las cursivas son nuestras.

(28) Las cursivas son nuestras. 
condiciones de trabajo del personal de la Ertzaintza para los años 2011, 2012 y 2013(29), por ejemplo, dispone en su art. 16.3 que «Con carácter general, cualquiera que sea el régimen de organización de trabajo en la Ertzaintza, entre el final de una jornada y el comienzo de la siguiente, mediarán como mínimo 12 horas de descanso. Asimismo entre cada semana de trabajo mediarán como mínimo 48 horas de descanso. Estas condiciones tendrán las correspondientes adecuaciones en cada tipo de régimen horario y no serán de aplicación en aquellos regímenes horarios en que así se prevea» (30).

De esta forma, el art. 19 de ese mismo Acuerdo estipula en su apdo. 5 que «En el régimen horario de turnos la jornada planificada diaria será de 8 horas, de lunes a viernes. En las jornadas planificadas de trabajo de los sábados y los domingos habrá 12 horas entre la hora de entrada y salida. Excepcionalmente, en el ciclo de tres semanas, podrá determinarse la prestación de las jornadas de Mañana y Tarde, en régimen de jornada partida». Ese mismo artículo, en su apdo. 6 II, permite la excepción «excepcional" de no descansar durante 12 horas: "Cuando, como consecuencia del cambio de turno, no pudiera ser respetado el descanso de doce horas hasta la hora de inicio de la jornada siguiente, el/la ertzaina podrá disfrutar de un permiso por todo el turno planificado de trabajo, siempre que lo permitieran las necesidades del servicio, siendo computado como de trabajo» (31). Incluso el art. 20 «in fine», en relación con las posibles permutas, es taxativo al consignar que "La realización de estas permutas no podrá tener como consecuencia el incumplimiento de las garantías de descanso" (las cursivas son nuestras). Y estas disposiciones se completan con el Anexo II que establece el régimen horario de turnos con horarios de entrada, por ejemplo, de 6:00 ó 7:00, el equipo del turno de mañana, y de 14:00 ó 15:00, el equipo del turno de tarde; de manera que no se superan las ocho horas diarias.

En cambio, en el caso del Servicio de Bomberos que prestan sus servicios para la Diputación Foral de Gipuzkoa, la excepción se convierte en norma. Para comenzar se recordará que ni la Ley 1/1996, de 3 de abril, de gestión de emergencias, ni el Anteproyecto de Ley reguladora de los servicios de prevención y extinción de incendios y salvamento de Euskadi 2015, como legislación específica, recogen nada que responda a esta duda que nos ocupa, de manera que, en principio, la normativa convencional abordaría el tiempo de trabajo del personal bombero a partir de una situación de anomia.

(29) BOPV de 20 enero 2012.

(30) Las cursivas son nuestras.

(31) Las cursivas son nuestras. 
Y así, por ejemplo, en el Acuerdo regulador de las condiciones de empleo del personal adscrito al Servicio de Bomberos de la Diputación Foral de Gipuzkoa de 10 de mayo de 2012 se implantan módulos de 24 horas de la forma que se expone a continuación. En el preámbulo del Acuerdo, las partes, tras declarar que "dicho sistema de trabajo resulta perfectamente compatible con las exigencias que se derivan del respeto a la normativa en materia de seguridad y salud laboral" y de asegurar que se trata de "un modo de organización del tiempo de trabajo muy frecuente en el entorno estatal y comunitario", adoptan una serie de compromisos para la implantación progresiva de la reorganización del servicio de bomberos. En lo que aquí interesa se destacarán, del Acuerdo, las condiciones relativas a los descansos entre turnos, las cuales se transcriben a continuación:

- Entre turnos existirá como mínimo un descanso de 48 horas

- No se trabajará más de 48 horas en un plazo de 7 días, siempre en periodos de cuatro meses, según lo dispuesto por la directiva europea

- Por lo demás, se cumplirá lo establecido en el acuerdo de 2006.

Al objeto de arrojar luz sobre el turno tan prolongado que se trabaja en el Servicio de Bomberos de Gipuzkoa, se quiere llamar la atención sobre las "Condiciones" recogidas en el propio Acuerdo. Efectivamente, «los turnos comenzarán al mediodía, a las 14:00 horas. No existirá una pausa para comer, es decir "quien entra, entrará comido, y quien salga, saldrá sin comer»; si bien el Acuerdo prevé que habrá una pausa «intrajornada" para cenar y para desayunar; siempre y cuando "no exijan un uso prolongado, siempre dentro del horario establecido para cenar y desayunar" y, huelga decirlo, se entiende que el personal se deberá encontrar en el centro de trabajo o, si se prefiere, dentro del ámbito de organización del servicio.

De todo lo anterior se colige que las tandas de los bomberos no son turnos de intervención excepcionales, como ocurre en los otros dos colectivos estudiados; algo que se evidencia al acudir al Calendario laboral del Servicio de Bomberos de la Diputación de Gipuzkoa para 2015, que establece un único módulo o turno de 24 horas(32), constituyéndose turnos cíclicos de 18 semanas. Durante las primeras seis semanas del primer semestre del año se trabajan 10 turnos de 24 horas, al cabo de los cuales los bomberos/as descansan durante tres semanas. $Y$ en el segundo semestre se repite el mismo esquema. El bombero/a trabaja un turno de 24 horas (de las 14:00 horas de un día a las 14:00 horas del siguiente) y

(32) Se sigue el documento Gipuzkoako Foru Aldundia: Criterios de sustitución y gestión de listas de bomberos. (Revisión noviembre 2015). 
estará disponible para trabajar otro turno de 24 horas pasados dos días, sin sobrepasar el límite de 48 horas de trabajo a la semana.

Llegados a este punto no puede obviarse la especial prestancia que se necesita para desempeñar el tipo de trabajo que realizan estos cuerpos de protección civil como tampoco los indeseables efectos que debe infligirles esa prolongación selectiva de jornadas. En efecto este supuesto plantea el interrogante de si es conforme a Derecho establecer la jornada en módulos de 24 horas continuadas, con o sin justificación excepcional que los avale.

Veamos a continuación cómo se pronuncia la legislación laboral.

\section{La normativa jurídico-laboral. Posible marco de referencia}

Al hilo de lo que se apuntaba en la Introducción de este trabajo, procede acudir también a la legislación laboral, norma de referencia de la administrativa en relación con las condiciones de trabajo del personal que presta sus servicios para las Administraciones Públicas (33).

De conformidad con el art. 34.1 del Estatuto de los Trabajadores (Real Decreto Legislativo 2/2015, de 23 de octubre, ET) "la duración máxima de la jornada ordinaria de trabajo será de cuarenta horas semanales de trabajo efectivo en cómputo anual».

A continuación, el mismo artículo dispone otros límites diarios, modificables por convenio colectivo o acuerdo de empresa, aunque lo que aquí interesa es que conforme al art. 34.3 ET, el mínimo de 12 horas de descanso diario es un límite de Derecho necesario absoluto, «tope legal de carácter absoluto en relación a cualquier sistema de ordenación del tiempo de trabajo» (34), no modificable ni por la autonomía colectiva ni por la autonomía individual de las partes (art. 3.5 ET). Y así, según el art. 34.3 ET «Entre el final de una jornada y el comienzo de la siguiente mediarán, como mínimo, doce horas» (35).

(33) Como expone la doctrina «Entre ambas normas tiene lugar un juego de remisiones - principalmente unilaterales, del EBEP hacia el ET- que no siempre permiten dilucidar con exactitud el régimen jurídico de una institución o un derecho propio del trabajo asalariados. Así sucede, de manera paradigmática, en relación con los derechos de jornada, permisos y vacaciones», GARCíA TORRES, A.: Ordenación del tiempo de trabajo, igualdad y corresponsabilidad en las Administraciones Autonómicas, CES, 2012, p. 104.

(34) LÓPEZ AHUMADA, J.E.: "Descansos semanales...», op. cit., p. 39, quien lo exceptúa de determinadas excepciones reglamentarias.

(35) El artículo continúa exigiendo que «El número de horas ordinarias de trabajo efectivo no podrá ser superior a nueve diarias, salvo que por convenio colectivo o, en su defecto, acuerdo entre la empresa y los representantes de los trabajadores, se establezca otra distribución del tiempo de trabajo diario, respetando en todo caso el descanso entre jornadas». La cursiva es nuestra. 
Este precepto está en total consonancia, como no podía ser de otra forma, con la legislación internacional en la materia. El Convenio de la OIT sobre las horas de trabajo (comercio y oficinas), 1930 (núm. 30), ratificado por España, prevé en su artículo 4 que "Las horas de trabajo por semana previstas en el artículo 3 podrán ser distribuídas [sic] de suerte que el trabajo de cada día no exceda de diez horas" (36).

El artículo es suficientemente claro respecto de su naturaleza de «ius cogens» en relación con el descanso diario pero, por si aún no fuera suficiente, el principio de irrenunciabilidad de derechos recogido en el art. 3.5 ET(37) se encarga de reforzarlo. En conclusión, ni siquiera cuando los trabajadores dependientes den su consentimiento - carente de vicios de nulidad-, bien a través de la autonomía individual, bien a través de la autonomía colectiva como serían los casos que nos ocupan (en el supuesto de que fuera aplicable), a la renuncia de una condición laboral reconocida por ley, como es ésta, se tomaría por ajustada a Derecho (38).

No obstante, respecto de esta materia, también debe acudirse al Real Decreto 1561/1995, 21 de septiembre, sobre jornadas especiales de trabajo (RJE), legislación que contempla distintas variaciones de jornada como de descansos en comparación con la legislación general prevista en el ET. Más específicamente, el RJE prevé expresamente unos descansos intrajornada de mayor duración que el previsto legalmente en el art. 34.3 ET, así como la distribución del descanso mejorado en atención a las exigencias de recuperación del trabajador/a y a la organización de la actividad laboral, según se trate de supuestos de ampliación o limitación del tiempo de trabajo diario. Pero la doctrina (39) también destaca que la autonomía colectiva o individual pueden determinar otros períodos de descanso comprendidos dentro de la jornada distintos de los previstos en la legislación laboral, "con el fin de reducir la extensión del trabajo continuado". Precisamente, ésta ha sido la opción contemplada en el RJE, que permite el pacto libre del descanso en determinas actividades no contempladas en la norma reglamentaria, de modo que su art. 1.2 «in fine» expresa que "Las disposiciones generales del Estatuto de los Trabajadores serán aplicables en cuanto no se opongan a las especiales que en este Real Decreto se establezcan».

(36) La cursiva es nuestra.

(37) Su texto indica que "Los trabajadores no podrán disponer válidamente, antes o después de su adquisición, de los derechos que tengan reconocidos por disposiciones legales de derecho necesario. Tampoco podrán disponer válidamente de los derechos que tengan reconocidos como indisponibles por convenios colectivos".

(38) En la doctrina, por todos, EZQUERRA ESCUDERO, L.: Tiempo de trabajo.., op. cit., p. 243.

(39) LÓPEZ AHUMADA, J.E.: "Los descansos comprendidos dentro de la jornada» su aplicación a las jornadas laborales de carácter especial», Temas Laborales, n. 27, 2004, p. 124-125. 
En el RJE existen trabajos donde se permite un reposo entre jornadas más reducido o acumulable en períodos más largos que una jornada. Sin embargo, como es normal, no se encuentra el trabajo de salvamento entre las jornadas ampliadas que permiten acumular el descanso entre jornadas; seguramente porque ese personal suele ser funcionario y/o interino. Pero el trabajo que realizan determinados servicios o unidades sanitarios, la Ertzaintza o el personal bombero podría "asimilarse» (40) al definido en la Sección 5. a del RJE con el rótulo «Trabajos en determinadas condiciones específicas". El art. 19 del RJE, titulado trabajo a turnos, permite en su enunciado, "cuando así lo requiera la organización del trabajo", que el día y medio de descanso semanal provisto por el ET, o bien se acumule "por períodos de hasta cuatro semanas" o bien se separe del día completo "para su disfrute en otro día de la semana». Ahora bien, respecto del descanso mínimo entre jornadas, la norma reglamentaria exige de nuevo que se disfrute, sin perjuicio de que cuando al cambiar el trabajador/a de turno de trabajo no pueda disfrutar del descanso mínimo entre jornadas de 12 horas, éste se reduzca, articulando, a su vez, dos garantías a favor del trabajador/a: que «en el día en que ocurra esa reducción» la duración del descanso sea, como mínimo, de siete horas; y compensándose la diferencia del descanso hasta las doce horas establecidas con carácter general en los días inmediatamente siguientes.

Conforme a esta legislación de desarrollo del ET, que en todo caso es excepcional al régimen de descanso entre jornadas de doce horas (art. 34.3 ET) y que se justifica por las necesidades organizativas de la empresa, que puede constituirse en turnos rotatorios o fijos (41), y dado que el personal que presta servicios de protección civil tienen una referencia

(40) Mayoritariamente, la doctrina entiende que sólo pueden acogerse al régimen especial de descansos del art. 19 las empresas en las que se realicen actividades por equipos de trabajadores en régimen de turnos rotatorios. La doctrina ha interpretado que por equipos de trabajadores a turnos hay que entender que se trata de turnos en el sentido del art. $36.3 \mathrm{LET}$, es decir, que se trata de lo que se conoce coloquialmente como turnos rotatorios, exigiéndose en consecuencia, que el trabajador ocupe sucesivamente el mismo puesto de trabajo en diferentes horarios a lo largo de un período de días o semanas. Queda excluida la aplicación de este régimen especial de descanso en lo que se conoce como turnos fijos, que propiamente no consisten en trabajo a turnos, ya que aunque el mismo puesto de trabajo se ocupa sucesivamente por varios trabajadores, éstos lo ocupan siempre en las mismas horas (turno fijo de mañana, de tarde) no cambiando, por tanto, de horario, vid. ALFONSO MELLADO, C.A. y PEÑA OBIOL, S.: Vacaciones, fiestas y descanso semanal, Valencia, Tirant lo Blanch, 1996, pág. 71; LÓPEZ AHUMADA, J.E.: Descansos laborales y tiempo de trabajo. Régimen de los descansos diario y semanal y de los días festivos, Madrid, Consejo Económico y Social, 2004, pág. 175.

(41) Comparto la postura defendida por CORRALES MORENO, M.A.: Condiciones laborales del trabajo nocturno. Tesis doctoral dirigida por L. López Cumbre. Universidad de Cantabria, 2016, p. 158159, conforme a la cual si no la Directiva, el art. 19 RJE se aplicaría a todo tipo de empresas que se organicen con turnos, sean éstos rotatorios (Directiva) o fijos. 
específica en la Directiva de 2003 como se verá más adelante(42), no sería conforme a Derecho la prestación de servicios efectuada ininterrumpidamente durante 24 horas; ya que la excepción al descanso entre jornadas de doce horas que prevé el art. 34.3 ET contempla un asueto de siete horas al día, algo que no ocurre en los turnos de 24 horas. Es cierto, y ya se ha advertido, que nos movemos en el ámbito de lo laboral, que no se corresponde con la naturaleza de los servicios prestados por los bomberos/as. Pero adviértase que, si por objeto de la actividad empresarial, se recurre a los descansos aminorados o más reducidos, su uso, en cualquier caso, debe ser restrictivo, además de tener que ir seguidos de una inmediata compensación. Se trata de supuestos en los que en virtud del cambio de turno no se pueda disfrutar de las doce horas de descanso que prescribe el art. 34.3 ET. En tales casos, y sólo en el día que así ocurra, podrá reducirse el descanso mínimo entre jornadas hasta un mínimo de siete horas. De tan estricta regulación se deduce que es imposible recurrir asiduamente a tales restricciones, y menos aun afectando sucesivamente a los mismos trabajadores/as (43).

En resumen, la normativa aplicable, claramente respecto de los trabajadores por cuenta ajena, es la ley, esto es, el art. 34.3 ET -interpretado conforme a la Directiva y su jurisprudencia según se observará más adelante-, de acuerdo con la jerarquía de normas que propugna la Constitución Española (art. 9), como el Estatuto de los Trabajadores (art. 3.3).

Sin embargo quizás la legislación comunitaria que ordena el tiempo de trabajo sea directamente aplicable porque, como se anticipaba más atrás, sí se refiere concretamente a los servicios de protección civil.

\section{La Directiva 2003/77/CE sobre aspectos de la ordenación del tiempo de trabajo y su transposición al ordenamiento español}

No cabe duda de que el tiempo de trabajo es una condición de trabajo pero, simultáneamente, se trata de una de las instituciones cuya regulación contribuye a la protección de la seguridad y la salud en el trabajo. Por este motivo la primera Directiva que abordó el tiempo de trabajo

(42) Entre los argumentos a favor de la aplicación de la definición legal, con base en la excepcionalidad misma de la regulación contenida en el art. 19 RDJE frente al régimen general de descansos, se ha indicado que, al afectar a la salud de los trabajadores, hay que aplicarla con carácter restrictivo, de tal forma que no se puedan beneficiar de este régimen especial aquellos supuestos a los que no se les aplicaría el resto de las normas proteccionistas referidas al concepto legal de trabajo a turnos, CARCELÉN GARCÍA. J.: El sistema de trabajo a turnos y su problemática, Madrid, Fundación Confemetal, 2000, pág 297.

(43) MORÓN PRIETO, R.: "Novedades en la ordenación de las jornadas especiales de trabajo», $R e$ laciones Laborales, n 1, 1997, pp. 9-10. LÓPEZ AHUMADA, J.E.: "Descansos semanales...», op. cit., p. 50. En ese mismo sentido, STSJ Castilla León/Valladolid, 16 octubre 2006, Ar. 2619 (F.J. 4). 
adoptó como base, aunque no sin falta de polémica (44), el desarrollo de la materia de seguridad y salud en el trabajo (45). Y la ordenación del tiempo de trabajo, con los períodos de descanso incluidos, constituye un principio general de la protección de la seguridad y de la salud de los trabajadores (46).Y, de nuevo, ese mandato de la Directiva aplicable también en el sector público no se ha desarrollado respecto del tiempo de trabajo en lo que se refiere a los/las funcionarios/as.

La solución adoptada por otro texto legal ligado directamente con la prevención de riesgos laborales, la Ley 31/1995, de 8 de noviembre, fue distinta ya que su articulado es tajante cuando mandata que se aplique al "personal con relación de carácter administrativo o estatutario y la Administración pública para la que presta servicios en los términos expresados en la disposición adicional tercera de esta Ley" (art. 3.1). Con todo, las disposiciones de la Directiva de 2003 relativas a la salud en relación con el tiempo de trabajo se han transpuesto básicamente en el Estatuto de los Trabajadores, norma jurídica de cuyo ámbito de aplicación se excluye el funcionariado (art. 1.3 ET). Aún así, merece la pena llamar la atención sobre la "propensión» de la legislación administrativa a importar a su ámbito las normas aplicables en el campo laboral relativas a las condiciones de trabajo de su personal.

El hecho de que convivan, en un mismo espacio, personal por cuenta ajena y personal estatutario y funcionario explica sin duda esa cierta homogeneización de sus condiciones laborales. En efecto, si acudimos a los estudios que se han realizado sobre la jornada y el descanso entre

(44) La misma se plasmó en el planteamiento de un recurso ante el Tribunal de Justicia de las Comunidades Europeas por el Reino Unido, que entendía que la base aducida, el artículo 118A del Tratado Constitutivo de la Unión Europea en la versión anterior al Tratado de Ámsterdam de 1997 era incorrecta. El Reino Unido interpuso recurso de anulación de la Directiva, siendo su razonamiento principal el hecho de que el tiempo de trabajo no se incardina en la seguridad y salud, sino entre las condiciones de trabajo. EITJCE resolvió en su sentencia 213/1996, de 12 de noviembre, As. C-84/1994, desestimando el recurso en su práctica totalidad, salvo en lo relativo al descanso semanal en domingo. La sentencia afirma de forma tajante que lo que regula la Directiva es la seguridad, la higiene y la salud de los trabajadores, y que a falta de otras precisiones los conceptos de seguridad y salud no deben interpretarse de forma restrictiva, en el sentido de que se refieren a todos los factores que pueden afectar a la salud y a la seguridad del trabajador. Por lo tanto, la sentencia declara que la ordenación del tiempo de trabajo no aparece necesariamente concebida como un instrumento de creación de la política de empleo y las medidas relativas a la ordenación del tiempo de trabajo que constituyen el objeto de la $\mathrm{Di}$ rectiva contribuyen directamente a la mejora de la protección de la seguridad y la salud de los trabajadores.

(45) La discusión sobre este carácter bifronte de la ordenación del tiempo de trabajo ha sido ampliamente reflejada en la doctrina, vid entre otros MERINO SENOVILLA, H.: "La jornada de trabajo", en AA.VV.: Coordinador VALDÉS DAL RÉ, F:: La reforma del mercado laboral, Lex Nova, Valladolid, 1994, pág. 375 y RIVERO LAMAS, J.: «Régimen de la jornada y los horarios en la reforma del Estatuto de los Trabajadores", Documentación Laboral, núm. 47, 1995, pág. 27.

(46) Sentencia Jaeger, citada, apdo.97. 
jornadas, resulta indudable que es más favorable para la salud del trabajador/a descansar entre jornadas (12 horas) que hacerlo de manera acumulada cada dos jornadas (turnos de 24 horas), sin perjuicio de otros intereses que pueden conducir a los trabajadores/as o funcionarios/as a preferir lo segundo. Recuérdese que el propio Preámbulo de la Directiva últimamente citada expone en su apdo. $4 .^{\circ}$ y bajo el enunciado "Utilidad de la directiva" que "La mejora de la seguridad, de la higiene y de la salud de los trabajadores en el trabajo representa un objetivo que no puede subordinarse a consideraciones de carácter puramente económico".

En esa línea, cabe reproducir también la Carta de Derechos Fundamentales de la UE (47). Aunque sus disposiciones son eficaces ante la UE y los Estados miembros sólo cuando se aplique el Derecho de la Unión (art. 51 y ss. de la Carta), por hallarnos precisamente en el terreno de la aplicación e interpretación de una directiva europea, ésta de 2003, su invocación es totalmente procedente. Efectivamente, el art. 31 de la Carta, bajo el rótulo "Condiciones de trabajo justas y equitativas"proclama que «Todo trabajador tiene derecho a trabajar en condiciones que respeten su salud, su seguridad y su dignidad" para reclamar a continuación que «Todo trabajador tiene derecho a la limitación de la duración máxima del trabajo y a períodos de descanso diarios y semanales, así como a un período de vacaciones anuales retribuidas» (48).

Las materias de la seguridad y la salud, y la limitación de la duración máxima de trabajo se contemplan en el mismo artículo, si bien en apartados diferentes. Pero se quiere arrojar luz sobre el hecho de que la Carta sitúa el descanso "en el día" (diario), asueto que en algún caso de los analizados en este trabajo no se contempla.

Al reparar de nuevo en la Directiva 2003/77/CE, no debe olvidarse el tenor imperativo o dispositivo de los artículos de la misma como, tan importante como lo anterior, el principio de mayor favorabilidad que viene ínsito en su articulado y que actúa en la relación entre el Derecho derivado de la Unión Europea y el Derecho estatal. Por una parte su artículo 2 dispone, con carácter general, que la Directiva establece las disposiciones mínimas de seguridad y salud en materia de ordenación del tiempo de trabajo (apdo. 1), para concretar a continuación que "se aplicará a) a los períodos mínimos de descanso diario, de descanso semanal y de vacaciones anuales, así como a las pausas y a la duración máxima de trabajo semanal, y b) a determinados aspectos del trabajo nocturno, del trabajo por turnos y del ritmo de trabajo" (apdo. 2).

(47) $2000 /$ C 364/01.

(48) La cursiva es nuestra. 
Como en cualquier directiva, también en ésta son especialmente interesantes los Considerandos de su Preámbulo. Y en él destaca la importancia que la Directiva presta a los períodos de descanso de los trabajadores. Tan es así que de diecisiete considerandos, entre los cuales varios son de carácter sistemático, el quinto apela a los «períodos de descanso adecuados" de los trabajadores, exigiéndose un descanso mínimo diario, semanal y anual, y períodos de pausa adecuados. El primer Considerando sustancial, esto es el cuarto, se destina a plasmar el gran objetivo al que se debe esta directiva: la mejora de la seguridad, de la higiene y de la salud de los trabajadores.

Otra de las temáticas o derechos sobre los que insiste este Preámbulo es el trabajo nocturno. De modo que de esos diecisiete considerandos, cinco se refieren expresamente al trabajo nocturno.

Ahora bien, antes de profundizar en los aspectos destacados más arriba, conviene adentrarnos en el binomio sector público-sector privado como campos de aplicación de esta Directiva.

\section{V.1. Aplicación de la Directiva 2003/88/CE al ámbito del sector público}

Se insistirá que la Directiva 2003/88/CE se aplica también al sector público (49). No obstante, su art. 2 , apdo. $3 .^{\circ}$ condiciona dicha aplicación en un doble sentido: "La presente Directiva se aplicará a todos los sectores de actividad, privados y públicos, en el sentido del artículo 2 de la Directiva 89/391/CEE, sin perjuicio de lo dispuesto en los artículos 14, 17, 18 y 19 de la presente Directiva", preceptos que contienen disposiciones referidas a algunas actividades de la protección civil.

La Directiva 89/391/CEE relativa a la aplicación de medidas para promover la mejora de la seguridad y de la salud de los trabajadores en el trabajo (50) delimitaba en sus incipientes artículos cuál era su ámbito de aplicación, descartándose su proyección (art. 2.2) "cuando se opongan a ello de manera concluyente las particularidades inherentes a determinadas actividades específicas de la función pública, por ejemplo, en las fuerzas armadas o la policía, o a determinadas actividades específicas en los servicios de protección civil. En este caso, será preciso velar para que la seguridad y la salud de los trabajadores queden aseguradas en la medida de lo posible, habida cuenta los objetivos de la presente Directiva» (51).

(49) Sobre las modificaciones que ha sufrido esta Directiva, véase FERRADANS CARAMÉS, C.: "La controvertida reforma de la directiva sobre la ordenación del tiempo de trabajo", Temas Laborales n. ${ }^{\circ} .86,2006$, pp. 97 y ss.

(50) DO L 183 de 29.6.1989, p. 1.

(51) La cursiva es nuestra. 
El Auto del Tribunal de Justicia de la Unión Europea de 14 de julio de 2005, haciendo alusión a la doctrina» Pfeiffer» (52), determinó que no cabía excluir del ámbito de aplicación de esa Directiva (se refería a la predecesora de la Directiva de 2003, la 93/104/CE) los servicios de protección civil en cuanto tales, sino "únicamente determinadas actividades específicas de dichos servicios cuyas particularidades se puedan oponer de manera concluyente a la aplicación de las normas enunciadas por la citada Directiva" (53).

La Directiva, al exceptuar determinadas actividades prestadas por la función pública o la protección civil del ámbito de su aplicación (art. 2.2, I) se refería, según el Auto delTribunal de Justicia de la Unión Europea citado, a "los servicios indispensables para la protección de la seguridad, de la salud y del orden públicos en circunstancias de especial gravedad y magnitud - por ejemplo, una catástrofe- que se caracterizan, en particular, por el hecho de que puedan exponer a los trabajadores a riesgos considerables en cuanto a su seguridad y/o a su salud y no se prestan, por naturaleza a una planificación del tiempo de trabajo de los equipos de intervención y de socorro" (54).

Y, más claramente, el citado Auto, en su apartado 51, expone que "las actividades ejercidas en condiciones normales en el seno de las fuerzas de seguridad y de socorro (...) se hallan incluidas dentro del ámbito de aplicación de la Directiva 89/391»; de modo que (apdo. 52) "esta Directiva debe aplicarse a las actividades de los bomberos, aun cuando éstas se ejerzan por la fuerzas de intervención sobre el terreno [...] dado que se realizan en condiciones habituales, conforme a la misión encomendada al servicio de que se trata, y ello aun cuando las intervenciones derivadas de dichas actividades sean, por su propia naturaleza, imprevisibles y puedan exponer a los trabajadores que las realicen a algunos riesgos para su seguridad y/o su salud" (55). Doctrina que encontrará la salvedad «en caso de catástrofes naturales o tecnológicas, los atentados accidentes graves u otros eventos de la misma índole, cuya gravedad y magnitud requieran la adopción de medidas indispensables para la protección de la vida, de la salud así como de la seguridad colectiva" (apdo. 54).

Como conclusión preliminar, por tanto, ninguna de las actividades prestadas por el personal de protección civil seleccionado en este trabajo

(52) Sentencia del Tribunal de Justicia (Gran Sala) UE de 5 de octubre de 2004. En los asuntos acumulados C-397/01 a C-403/01

Asimismo cabe citar la STJUE Feuerwehr Hamburg, de 14 julio 2005.

(53) C 52/04, Considerando n. ${ }^{\circ} 45$

(54) Apartado 45

(55) La cursiva es nuestra. 
está excluida, de base, del ámbito de aplicación de la Directiva; aunque sí será posible excluir la aplicación de algunas normas particulares de la misma a los servicios de protección civil, como se verá más adelante.

Antes de emprender esa otra tarea, quizás convenga ahora delimitar correctamente qué es tiempo de trabajo y qué es tiempo de descanso; y ello en aras de revelar si los turnos que instauran algunos Acuerdos reguladores que estamos analizando se corresponden en su totalidad con el trabajo efectivo.

\section{V.2. Distinción entre tiempo de trabajo y tiempo de descanso a la luz de la Directiva y de su jurisprudencia}

En el artículo 2 de la Directiva 2003/88/CE se define el tiempo de trabajo como «todo período durante el cual el trabajador permanece en el trabajo, a disposición del empresario y en ejercicio de su actividad o de sus funciones, de conformidad con las legislaciones y/o prácticas nacionales». Y el período de descanso (56), por exclusión, se caracteriza como todo período que no sea tiempo de trabajo. En la Directiva no existe ninguna categoría intermedia, por lo que un período concreto de actividad sólo puede ser considerado tiempo de trabajo o de descanso.

Por eso, conforme a la Directiva, será considerado "tiempo de trabajo» permanecer durante 24 horas en el puesto de trabajo, en el caso de los bomberos/as, de ordinario; y en el del personal de determinados servicios o unidades sanitarias, excepcionalmente; y habrá que distinguirlo de los "tiempo de presencia», "tiempos de disponibilidad" o "tiempos de guardia o retén", que en cualquier caso deben reputarse asimismo tiempo de trabajo conforme a la Directiva 2003/88/CE - tiempo con una naturaleza diferente (57), también Ilamado «de subordinación» (58).

(56) ALARCÓN CARACUEL, M. R.: La ordenación..., op. cit., p. 94 criticó la alusión al «lisa y llanamente tiempo libre" como "tiempo de descanso" porque ello "es colocarse en la rampa de lanzamiento de la mistificación en cuanto se toma el tiempo de trabajo como la única referencia incluso para tomar el tiempo libre».

(57) GÓMEZ MUÑOZ, J.M.: Las jornadas especiales de trabajo. Aranzadi, Pamplona, 1999, p. 119. Asimismo, una jurisprudencia antigua ha separado tradicionalmente la jornada de trabajo efectivo del tiempo de presencia, en atención a la diferente naturaleza y finalidad de ambos tiempos, cfr., EZQUERRA ESCUDERO, L.: Tiempo de trabajo: duración, ordenación y distribución, UGT/Atelier, Barcelona, p. 78-79.

(58) LÓPEZ AHUMADA, J.E.: "Descansos semanales...», op. cit., p. 55. Incluso tratándose de ese híbrido entre el trabajo efectivo y el descanso, el autor alerta de que también en estos supuestos se tendría que respetar el descanso mínimo diario.

Para abundar en esa distinción, una reciente sentencia del TJUE de 10 marzo 2015 (asunto C266/14) ha determinado que el tiempo de desplazamiento de los trabajadores que carezcan de centro de trabajo fijo, entre su domicilio y los del primer y del último cliente del día, es también tiempo de trabajo. 
Naturaleza distinta tendrían las guardias de localización sin presencia física, que no computarían como trabajo efectivo (59) salvo que realmente se realice (60). Sin embargo, no es éste el caso del personal sanitario y bombero analizado, cuyo trabajo obviamente discurrirá por períodos de baja o nula actividad, aunque "la exigencia de estar realizando "su actividad" no se puede interpretar como una actividad realizada constante y sin parar un segundo"; pudiendo "darse casos momentos en que se produzca un bajo índice de actividad o esta se produzca con una cierta intermitencia lo que no impedirá la exigencia al trabajador de una disponibilidad actual y presente para el ejercicio de la misma" (61). En conclusión, los acuerdos objeto de este comentario regulan que cierto personal sanitario trabaje 24 horas seguidas, o que los bomberos/as trabajen ordinariamente en módulos de 24 horas seguidas, con dos pautas intra-jornada $y$, en principio, sin asueto para dormir.

Con el objeto de lograr una mayor precisión en torno a esta materia, y dado que se supone que todo el tiempo que los sanitarios y los bomberos/as permanecen en sus puestos, cuando realizan módulos de 24 horas, no desarrollarán un trabajo efectivo $-y$ si lo hacen, con más razón será ese tiempo considerado "de trabajo» de conformidad con la distinción entre "tiempo de trabajo" y "descanso" que efectúa la Directiva -, es pertinente traer a colación la doctrina emitida por el TJUE, en los casos SIMAP y JAEGER, sentencias, de 3 de octubre de 2000 y de 9

(59) MARTíNEZ YÁÑEZ, N.: «Tiempo de descanso y período de descanso en la Directiva 03/88/CE y en la jurisprudencia del Tribunal de Justicia de las Comunidades Europeas", RDS, n. 25, 2004 p. 137, reconoce que las sentencias del TJ no declaran que el tiempo empleado en las guardias de localización sin intervención efectiva constituyan tiempo de descanso aunque esa conclusión se imponga con "rigor lógico», debido a la única disyuntiva que permite la Directiva citada entre tiempo de trabajo ("en ejercicio de su actividad») o tiempo de descanso.

En el ámbito de la CAPV, véase, a modo de ejemplo, el artículo 29 "Duración máxima conjunta de los tiempos de trabajo" del Acuerdo regulador de las condiciones de trabajo del personal de Osakidetza-Servicio vasco de salud, para los años 2007, 2008 y 2009 (BOPV 27 Mayo 2013), que recoge que «No serán tomados en consideración para la duración máxima conjunta de los tiempos de trabajo correspondientes a la jornada ordinaria y a la jornada complementaria, los períodos de localización, salvo que el personal sea requerido para la prestación de un trabajo o servicio efectivo, caso en que se computará como jornada tanto la duración del trabajo desarrollado como los tiempos de desplazamiento, computándose este tiempo de desplazamiento por un máximo de media hora.

En ningún caso se computarán a estos efectos las jornadas ordinarias no realizadas efectivamente, en cuanto tiempo que el personal no permanece en su Organización de servicios a disposición del centro y en el ejercicio efectivo de sus actividades y funciones».

(60) SsTJUE SIMAP vs Consejería de Sanidad y Consumo de la Generalitat Valenciana, Asunto C-303/98, de 3 de octubre de 2000; y JAEGER y KIEL, de 9 de septiembre de 2003, Asunto C-151/02, apdos. 50 y 65 , respectivamente.

(61) EZQUERRA ESCUDERO, L.: Tiempo de trabajo.., op. cit., p. 239, quien lo compara con el trabajo en el mar. 
de septiembre de 2003, respectivamente (62). EITJUE afirma que los tres elementos característicos del tiempo de trabajo - según el artículo 2.1 de la vigente Directiva 2003/88/CE, de 4 noviembre, esto es, el período durante el que el trabajador permanece en el trabajo, a disposición del empresario y en el ejercicio de su actividad o de sus funciones, de conformidad con las legislaciones y/o prácticas nacionales (63) - , concurren únicamente cuando el personal está presente en el centro de trabajo, y no por el mero hecho de estar localizable, pues en este caso sólo debe entenderse como tiempo de trabajo el correspondiente a la efectiva prestación de servicios (64).

Merece la pena traer a colación el caso de la Sentencia JAEGER y KIEL (65), por tratarse de un supuesto de personal médico, ya que se refería a un servicio de atención continuada que efectúa un médico en régimen de presencia física en el hospital. Para el Tribunal ese tiempo constituye en su totalidad tiempo de trabajo a efectos de la entonces vigente Directiva 93/104/CEE, aun cuando al interesado se le permita descansar en su lugar de trabajo durante los períodos en que no se soliciten sus servicios. Nos hallamos, pues, ante un "concepto restrictivo" (66) de la noción de tiempo de trabajo. En la sentencia citada (apdos. 94, 95 y 97), el Tribunal indica que durante los períodos de descanso, el trabajador debe contar con la posibilidad de abandonar su entorno laboral.

(62) Cfr. la STJUE SIMAP vs Consejería de Sanidad y Consumo de la Generalitat Valenciana, Asunto C-303/98, de 3 de octubre de 2000, en la que se plantea al Alto Tribunal si cuando los médicos que realizan turnos de atención continuada (guardias), mediante los dos sistemas posibles, de localización y de presencia física, debe estimarse todo este tiempo como de trabajo o sólo aquél efectivamente invertido en la realización de la actividad para la que son llamados, decantándose el TJ por la segunda opción.

(63) Para profundizar más en esta jurisprudencia, cfr. MARTíNEZ YÁÑEZ, N.: «Tiempo de descanso......, op. cit., pp. 121 y ss, quien opina que una interpretación literal de la definición comunitaria de tiempo de trabajo forzaría a excluir del mismo situaciones como las guardias de presencia física, lbídem, p. 150.

(64) EI TJUE en su sentencia SIMAP manifestó que «el tiempo dedicado a la atención continuada prestado por los médicos de equipos de atención primaria, bien mediante el régimen de presencia física en los centros sanitarios debe considerarse tiempo de trabajo en su totalidad y, en su caso, horas extraordinarias en el sentido de la Directiva 93/104. Por lo que respecta a la prestación de servicios de atención continuada por dichos médicos en régimen de localización sólo debe considerarse tiempo de trabajo el correspondiente a la prestación efectiva de servicios de atención primaria». Secundando esta doctrina por la que los elementos característicos del tiempo de trabajo son las obligaciones de hallarse físicamente presente en el lugar determinado por el empresario y de permanecer a disposición de éste para poder prestar inmediatamente servicios en caso de necesidad, vid en la jurisprudencia española, entre otras, STSJ de Galicia, de 21 de marzo de 2001, Ar. 2128 y STSJ de Aragón, de 18 de marzo de 2002, Ar. 922.

(65) STJCE JAEGER y KIEL, de 9 de septiembre de 2003, Asunto C-151/02.

(66) MARTíNEZYÁÑEZ, N.: «Tiempo de descanso y período de descanso...», op. cit., p. 132. 
Y sin embargo, el art. 3 de la Directiva contempla que "Los Estados miembros adoptarán las medidas necesarias para que todos los trabajadores disfruten de un período mínimo de descanso diario de 11 horas consecutivas en el curso de cada período de 24 horas".

En conclusión, entonces, y de conformidad con la Directiva, las horas, $X$, de presencia en el centro de trabajo - o de estar en el ámbito de organización correspondiente-, que se determinen en los acuerdos reguladores de los funcionarios deben reputarse como de "trabajo efectivo" y los sujetos negociadores no estarían facultados para alterar la obligación de descansar, mínimamente durante 11 horas consecutivas en un "período de 24 horas".

Es visible, y se ha observado más atrás, que la regulación del trabajo por cuenta ajena en el ordenamiento jurídico-laboral español mejora la duración del descanso entre jornadas. Sin embargo, en relación con el sintagma temporal "en el curso de cada período de 24 horas» (art. 3 Directiva), la doctrina científica, comparándolo de nuevo con el art. $34.3 \mathrm{ET}$, ha sostenido que "precisamente, en la normación comunitaria del descanso entre jornadas aparece con mayor nitidez el carácter diario del reposo, cosa que no se aprecia en nuestro ordenamiento jurídico cuya regulación es más abstracta»(67). En efecto, conforme a la redacción del art. 34.3 ET, en un supuesto puramente teórico, podría ser ajustada a Derecho una jornada de 18 o 20 horas, siempre que una vez finalizada ésta, descansase el trabajador/a durante doce horas hasta la siguiente; pero esas jornadas tan alargadas y concentradas no serían conformes a Derecho de acuerdo con la Directiva 2003 (68).

Por si no fuera suficiente, el art. 5 de la norma comunitaria, al regular el descanso semanal, de 24 horas ininterrumpidas, separa éste del descanso (diario) que recoge el art. 3, "a las [24 horas] que se añadirán las 11 horas de descanso diario establecidas en el artículo 3» (69).Y su art. 6, mirando el lapso semanal, exhorta a que "la duración media de trabajo no exceda de 48 horas, incluidas las horas extraordinarias por cada período de siete días". Tal como se decía más atrás, el primer límite, que es más expreso y exhaustivo que el contemplado para el trabajo por cuenta ajena en la legislación jurídico-laboral española - aunque aquél también ha sido objeto de crítica ya que la Directiva parece anclada en el modelo

(67) LÓPEZ AHUMADA, J.E.: Descansos laborales y tiempo de trabajo..., op. cit., p. 42, y doctrina allí citada. La cursiva es nuestra. Así también EZQUERRA ESCUDERO, L.: Tiempo de trabajo.. op. cit., p. 244, muy contundente cuando expresa que el art. 3 de la Directiva califica como descanso diario el descanso que regula.

(68) Cfr., EZQUERRA ESCUDERO, L.: Tiempo de trabajo.., op. cit., pp. 253 y 255.

(69) La cursiva es nuestra. 
fordista al formular los conceptos de tiempo de trabajo y descanso(70), no se respeta en algunos de los acuerdos objeto de este comentario. Pero para reforzar esta anticipada conclusión, conviene volver a traer a colación la sentencia JAEGER del TJUE que declaró contraria a la Directiva una práctica consistente en acumular varios períodos de trabajo, aplazando el disfrute del correspondiente tiempo de descanso(71).

Además, ha de recordarse que para el TJUE las diferentes disposiciones en materia de tiempo mínimo de descanso constituyen normas del Derecho social comunitario de especial importancia. Por ello esa regulación actúa a modo de "disposiciones mínimas necesarias para garantizar la protección de su seguridad y salud» (72).

La Directiva, hasta lo ahora analizado, recoge normas de mínimos en los preceptos vistos. Pero todavía queda por analizar si esta regulación jurídica de la Directiva puede ser objeto de excepción por que lo faculte la propia norma comunitaria.

\section{V.3. Las disposiciones de la Directiva que permiten exceptuar la aplicación de algunos de sus contenidos en un Estado miembro}

Del texto del art. 17 de la norma europea se desprende que ésta permite una aplicación atenuada de algunas de sus disposiciones mínimas, aunque, con la Sentencia Jaeger citada (73) "sólo en circunstancias excepcionales permite el art. 17 que se conceda a los trabajadores otra "»protección adecuada», cuando la concesión de períodos equivalentes de descanso compensatorio no sea posible por razones objetivas» (74); doctrina que descarta excluir del ámbito de aplicación de la Directiva, las actividades ejercidas en condiciones normales por las fuerzas de seguridad y de socorro.

En efecto, la Directiva permite en su art. 17.3 - posibilita- articular ciertas excepciones respecto de determinadas disposiciones, precepto que se completa con lo previsto en el art. 17.2. La actividad del personal de protección civil examinado en este trabajo se incluye, expresamente, en el art. 17.3, letras i), iii). El contenido de este precepto puede analizarse

(70) MARTÍNEZYAÑEZ, N.: "Tiempo de descanso y período de descanso...", op. cit., p. 143-144.Sobre el descanso, la autora aboga por una redefinición del mismo a partir de un contenido material positivo, ibídem, p.p. 144 y ss.

(71) Apartados 95 y 96.

(72) Cfr. SSTJUE BECTU, apdos. 43 y 47; Comisión/Reino Unido 7 de septiembre de 2006, C 484/04, apdo. 38 y, más concretamente, Sentencia Isere, apdo. 36

(73) Nos remitimos al epígrafe V.1.

(74) STJUE citada, apdo. 98. 
en función de dos criterios: la materia y la forma que reclama para albergar esas excepciones.

-En primer lugar, en relación con el «qué», el apdo. $3 .^{\circ}$ del art. 17 permite la excepción de lo dispuesto en los arts. 3, 4, 5, 8 y 16 de la Directiva 2003/88/CE, - preceptos relativos a los distintos tipos de descansos y a la duración semanal del tiempo de trabajo; y a lo dispuesto en los arts. 8 (duración del trabajo nocturno) y 16 (períodos de referencia)-, "para las actividades caracterizadas por la necesidad de garantizar la continuidad del servicio o de la producción...". Ese apartado lista esas posibles actividades, excepcionables, y entre ellas se encuentran los servicios relativos a la recepción, tratamiento y/o asistencia médica prestados por hospitales o centros similares -incluyendo las actividades de médicos en períodos de formación [art. 17.3 c) i] y de bomberos y protección civil (iii).

-Pero tan importante como lo anterior es el "cómo", esto es, cuáles son los instrumentos apropiados para alojar esas excepciones; de modo que éstas podrán establecerse mediante instrumentos jurídicos muy diversos (apdo. 2. del art. 17) como procedimientos legales, reglamentarios o administrativos o convenios colectivos o acuerdos celebrados entre interlocutores sociales. Con todo, también este apartado determina cuál es el Derecho inderogable que debe respetarse aún cuando se articulen esas excepciones, que está constituido por dos mínimos: i) que se concedan períodos equivalentes de descanso compensatorio a los trabajadores de que se trate $y$, (ii) si lo anterior no es posible por tratarse de «casos excepcionales en que por razones objetivas no sea posible la concesión de tales períodos equivalentes de descanso compensatorio, se conceda una protección equivalente a los trabajadores de que se trate».

La jurisprudencia de la Unión Europea (75) es muy clara respecto de dichos mínimos cuando declara que "las excepciones a las que se refiere el artículo 17 deben ser objeto de una interpretación que limite su alcance a lo estrictamente necesario para salvaguardar los intereses que estas excepciones permiten proteger» (76).

En los casos que nos ocupan, como se veía más atrás, ni el Estado ni la CAPV amparándose en el citado art. 17 de la Directiva, han dictado normas jurídicas de desarrollo (salvo alusiones genéricas al «descanso necesario", etc., que ya hemos citado) respecto de los colectivos examinados.

(75) Véase, de nuevo, la Sentencia JAEGER, esp. Apdo. 88 y ss.

(76) Véase, de nuevo, la Sentencia JAEGER, esp. Apdo. 89. 
En tanto que la Directiva, en el art. 17, sitúa en el mismo plano de igualdad a los procedimientos legales y a los convenios colectivos o acuerdos entre los interlocutores sociales, como instrumentos con capacidad de contemplar dichas excepciones, podría colegirse que los acuerdos reguladores de las condiciones de trabajo revisados en este artículo podrían exceptuar el descanso inter-jornadas. Es decir, los casos analizados en este trabajo se ajustarían a lo dispuesto en la Directiva tanto por el "qué" cuanto por el "cómo". Aunque se albergan serias dudas respecto del cumplimiento de las disposiciones mínimas que dichos acuerdos deben respetar, aún cuando desarrollen las excepciones permitidas por el art. 17 de la Directiva.

En efecto, tanto el Acuerdo de Osakidetza como el de la Ertzaintza-Policía vasca advierten en su articulado que las excepciones contempladas respecto del descanso son debidas a circunstancias excepcionales; de modo que la hipótesis adelantada en este trabajo (77) que planteaba que el tiempo de trabajo fuera subyugado al destacado interés general que garantizan esos servicios, y su personal, no puede elevarse a tesis. En cambio, volviendo a reparar en el trabajo prestado por los Bomberos de Gipuzkoa, éste sigue presentándose como el caso más polémico de los aquí revisados por no someterse a ninguna condición particular, objetiva ni excepcional.

Antes de avanzar una conclusión definitiva, conviene detenerse en el hecho de que el trabajo de los bomberos de Gipuzkoa se desarrolla en régimen de módulos y ocupa, al mismo tiempo que la franja diurna, la nocturna -como también la ocupan ciertos servicios sanitarios en situaciones especiales; por lo que procede acudir a la regulación del trabajo nocturno en concreto (art. 8, esencialmente), cuya regulación puede exceptuarse, además, por lo previsto en el art. 18 de la Directiva.

\section{V.4. Tiempo de trabajo nocturno}

Se constataba más arriba que parte de esas «jornadas" de trabajo de determinados servicios o unidades sanitarias de Osakidetza pueden alargarse hasta 24 horas «con carácter excepcional y cuando así lo aconsejen razones organizativas o asistenciales» (78). En el caso de la Ertzaintza, sin fijarse una cantidad de horas determinada, se avala, excepcionalmente, no descansar durante 12 horas "como consecuencia del cambio de turno». Aunque Ilama más la atención el caso del personal bombero,

(77) Véase el apartado III.2.

(78) Nos remitimos a los acuerdos citados más atrás. 
cuyo Acuerdo, bajo ninguna condición, provee turnos de 24 horas seguidas, que obviamente, copan el lapso del trabajo nocturno.

Y la Directiva 2003/88/CE, advierte ya en su Exposición de Motivos (apdo. 7) que "Ciertos estudios han demostrado que el organismo humano es especialmente sensible durante la noche a las perturbaciones ambientales, así como a determinadas modalidades penosas de organización del trabajo, y que los períodos largos de trabajo nocturno son perjudiciales para la salud de los trabajadores y pueden poner en peligro su seguridad en el trabajo".

La Directiva, en su Exposición de Motivos (apdo. 6. ${ }^{\circ}$ ) anota también que conviene tener en cuenta los principios de la Organización Internacional delTrabajo por lo que respecta a la distribución del tiempo de trabajo, incluidos los que se refieren al trabajo nocturno; igualmente observa (apdo. $7^{\circ}$ ) que "Ciertos estudios han demostrado que el organismo humano es especialmente sensible durante la noche a las perturbaciones ambientales, así como a determinadas modalidades penosas de organización del trabajo, y que los períodos largos de trabajo nocturno son perjudiciales para la salud de los trabajadores y pueden poner en peligro su seguridad en el trabajo".

El desarrollo de esas previsiones se recoge en el art. 8 de la Directiva, titulado "Duración del trabajo nocturno", pero antes es importante reparar en ciertas definiciones que realiza el art. 2 de la Directiva en relación con este tipo de trabajo. En efecto, de conformidad con el art. 2.3) se define como período nocturno «todo período no inferior a siete horas, definido por la legislación nacional, y que deberá incluir, en cualquier caso, el intervalo comprendido entre las 24.00 horas y las 5.00 horas. A continuación el apdo. 4) de ese art. 2 describe al trabajador nocturno en base a dos parámetros:

a) por una parte, todo trabajador que realice durante el período nocturno una parte no inferior a tres horas de su tiempo de trabajo diario, realizadas normalmente(79), y

b) por otra parte, todo trabajador que pueda realizar durante el período nocturno determinada parte de su tiempo de trabajo anual, definida a elección del Estado miembro de que se trate:

i) por la legislación nacional, previa consulta a los interlocutores sociales, o

ii) por convenios colectivos o acuerdos celebrados entre interlocutores sociales a nivel nacional o regional;

(79) La cursiva es nuestra. 
Más adelante, el art. 8 encomienda a los Estados miembros a adoptar obligatoriamente las medidas necesarias para proteger a estos trabajadores (80), sin que ni la autonomía individual ni la autonomía colectiva puedan superar y por tanto, contrariar(81) el máximo contemplado por la norma comunitaria: «Los Estados miembros adoptarán las medidas necesarias para que a) el tiempo de trabajo normal de los trabajadores nocturnos no exceda de ocho horas como media por cada período de 24 horas".

Pero todavía es más interesante que en función del tipo de trabajo que se preste $y$, sobre todo, cuando éste implique "riesgos especiales o tensiones físicas o mentales importantes", algo que no es difícil atribuir a los servicios médicos, de policía y de salvamento, la duración del trabajo efectivo no supere nunca las ocho horas en un período de referencia de 24 horas. En concreto su enunciado es el que sigue: «b) los trabajadores nocturnos cuyo trabajo implique riesgos especiales o tensiones físicas o mentales importantes no trabajen más de ocho horas en el curso de un período de 24 horas durante el cual realicen un trabajo nocturno" (art. 8 Directiva). A los efectos de la letra b), continúa señalando el mismo precepto que «el trabajo que implique riesgos especiales o tensiones físicas o mentales importantes será definido por las legislaciones y/o las prácticas nacionales, o por convenios colectivos o acuerdos celebrados entre interlocutores sociales, tomando en consideración los efectos y los riesgos inherentes al trabajo nocturno».

En 2016, a raíz del Dictamen Motivado 2014/4169 dirigido por la Comisión Europea al Reino de España, se reprochó a este país que no hubiera transpuesto correctamente el límite absoluto de ocho horas para el trabajo nocturno que implique riesgos especiales o tensiones importantes, previsto en el artículo 8, letra b), de la Directiva, se aprobó el Real Decreto 311/2016, de 29 de julio, por el que se modifica el Real Decreto 1561/1995, de 21 de septiembre, sobre jornadas especiales de trabajo, en materia de trabajo nocturno (también previsto en el art. 36 ET). Con este reglamento se añade un nuevo artículo (33) titulado "Jornada máxima de los trabajadores nocturnos en trabajos con riesgos especiales o tensiones importantes" con la siguiente redacción: 1) "La jornada de trabajo máxima de los trabajadores nocturnos cuyo trabajo implique riesgos especiales o tensiones físicas o mentales importantes será de ocho horas en el curso de un periodo de veinticuatro horas durante el cual realicen un trabajo nocturno, salvo que deba ser inferior, según lo previsto en el capítulo III. A efectos de lo dispuesto en este artículo los trabajos que impliquen ries-

(80) Desde la propia Exposición de Motivos, la Directiva se emplea a fondo con el trabajo nocturno.

(81) Sí podrán mejorarlo, conforme dispone el art. 15 de la Directiva. 
gos especiales o tensiones físicas o mentales importantes serán los definidos como tales en convenio colectivo o, en su defecto, por acuerdo entre la empresa y los representantes de los trabajadores, tomando en consideración los efectos y los riesgos inherentes al trabajo nocturno. Y 2) la jornada de trabajo máxima de los trabajadores nocturnos establecida en el apartado 1 sólo podrá superarse en los supuestos previstos en el artículo 32.1.b) y c).»

El denominador común de la jornada de trabajo de los que trabajan en turnos de noche (es decir, los trabajadores nocturnos en general) debe ser de 8 horas en un período de referencia de 24 horas. 0 lo que es lo mismo y, por ejemplo, aquellos podrán trabajar un lunes 9 horas y el martes, 7 horas; pero, en ningún caso, lógicamente, podrán acumularse al trabajo nocturno otros dos turnos, de mañana y de tarde.

En relación con el funcionariado en general, el EBEP no se pronuncia en relación con el trabajo nocturno, ni tampoco se dedica a describir qué trabajadores lo son por copar parte de ese horario.

Por su parte, el art. 3 del Anteproyecto de Ley reguladora de los servicios de prevención y extinción de incendios y salvamento de Euskadi 2015 (82), intitulado "Naturaleza y funciones», no define el personal ocupado de prestar esos servicios, pero sí los retrata como «uno de los servicios esenciales o básicos del sistema vasco de atención de emergencias y protección civil de conformidad con lo dispuesto en el artículo 60.2 de la Ley 15/2012, de 28 de junio, de Ordenación del Sistema de Seguridad Pública de Euskadi»; de modo que podemos considerar al personal de la policía vasca, al personal médico de urgencias o a los bomberos como trabajadores/as con un trabajo que entraña riesgos especiales o tensiones físicas o mentales importantes. Y, con la Directiva como referencia, parece claro que, por lo menos el personal bombero se inscribe en la definición de trabajador nocturno.

Por ello, entiendo que el personal de la Ertzaintza, el personal sanitario de urgencias o los bomberos/as no podrían trabajar ordinariamente más de 8 horas cuando realicen un trabajo nocturno. Y esta prohibición se vulnera en todos los turnos de 24 horas de trabajo efectivo que prevé el Acuerdo regulador del servicio de bomberos. Y, tampoco ese descanso tras esas excesivas jornadas de trabajo parece adecuado, no ya tanto por el "quantum" sino por el "cuándo". Y así, el apdo. 9) del art. 1 Directiva 2003/88/CE califica de «descanso adecuado" los "períodos regulares de descanso de los trabajadores, cuya duración se expresa en unidades de tiempo, suficientemente largos y continuos para evitar que, debido al cansancio o a ritmos de trabajo

(82) https://www.irekia.euskadi.eus/uploads/attachments/5435/Anteproyecto_de_Ley.pdf?1415968247 
irregulares, aquellos se produzcan lesiones a sí mismos, o a sus compañeros o a terceros, y que perjudiquen su salud, a corto o a largo plazo". Pero antes de emitir un juicio final es oportuno analizar los cauces que permiten exceptuar las previsiones de la Directiva relativas al trabajo nocturno.

\section{V.4.1. LOS INSTRUMENTOS JURÍDICOS AÑADIDOS QUE SIRVEN PARA ARTICULAR EXCEPCIONES A LAS DISPOSICIONES SOBRE TRABAJO NOCTURNO}

La vía apropiada para exceptuar las previsiones relativas a la duración del trabajo nocturno regulado en el art. 8 de la Directiva, $y$, en parte, en el art. 16 (períodos de referencia), encuentra soporte jurídico en el art. 17 de la misma (analizado en un apartado anterior); pero, además, el art. 18 de la Directiva, intitulado "Excepciones mediante convenios colectivos" habilita otro importante cauce de excepción, que no sólo sirve para el trabajo nocturno, sino también para las materias reguladas en los arts. 3, 4 y 5. Esos instrumentos añadidos consisten en "los convenios colectivos o acuerdos celebrados entre interlocutores sociales a nivel nacional o regional o, de conformidad con las normas fijadas por dichos interlocutores sociales, mediante convenios colectivos o acuerdos celebrados entre interlocutores sociales a un nivel inferior»(83). En esa misma línea, el art. 16.c) de la Directiva - «Períodos de referencia»- permite a los Estados miembros relajar esos períodos del trabajo nocturno «previa consulta a los interlocutores sociales o mediante convenios colectivos o acuerdos colectivos celebrados a nivel nacional o regional entre interlocutores sociales" (84).

Es pertinente analizar este otro tipo de repositorio dado que el artículo 18 no se refiere a los mínimos inderogables que prevé el art. 17.2 de la Directiva; aunque, como contrapartida, aquél se remite a un tipo de negociación colectiva cuyos sujetos legitimados ostentan una representatividad muy cualificada.

El ordenamiento jurídico-laboral español observa la existencia de acuerdos interprofesionales (art. $83 \mathrm{ET}$ ) que facultan a los interlocutores sociales de ámbito estatal o de ámbito de CC.AA. (regional) a determinar esas excepciones. Por tanto, a ellos competería la posibilidad de regular esas excepciones. La legitimación tan cualificada que se avanzaba "supra" responde al dato que esa negociación les correspondería a los sindicatos y asociaciones más representativas del ámbito del Estado y

(83) La cursiva es nuestra.

(84) La cursiva es nuestra. 
de la Comunidad Autónoma (85). Y por lo anterior no sería aplicable en España el segundo párrafo del art. 18 Directiva 2003/88/CE en el sentido de que sólo en el caso de "Los Estados miembros en los que jurídicamente no exista un sistema que garantice la celebración de convenios colectivos o de acuerdos entre interlocutores sociales a nivel nacional o regional en las materias de que trata la presente Directiva, o en los que exista un marco legislativo específico para tal fin y dentro de los límites del mismo, podrán, de conformidad con la legislación y/o prácticas nacionales, permitir excepciones a las disposiciones de los artículos 3, 4, 5,8 y 16 mediante convenios colectivos o acuerdos celebrados entre interlocutores sociales al nivel colectivo apropiado(86)".

Respecto de esta última posibilidad tampoco se conoce que se haya adoptado en España ningún convenio o acuerdo colectivo de esa naturaleza que incluya esas excepciones. Así, por ejemplo, en el ámbito laboral, el instrumento adecuado podía ser el III Acuerdo sobre Negociación Colectiva (ANC) (87). El apdo. 2 del Capítulo IV de dicho ANC relativo a la jornada es el que más se aproxima, por contenido al tema que nos ocupa. Éste es su texto:

"Los convenios sectoriales y especialmente los provinciales, por su proximidad a la empresa, deberían fijar las reglas generales de la flexibilidad del tiempo de trabajo.

Por su parte, los convenios sectoriales promoverán una adaptación negociada en el ámbito de la empresa de lo pactado en el sector, con participación de la representación de los trabajadores o, en su defecto, negociada con las organizaciones sindicales firmantes del convenio sectorial.

Asimismo, los convenios, especialmente los de empresa, debieran promover la racionalización del horario de trabajo, teniendo en cuenta las especificidades de cada sector o empresa, con el objetivo de mejorar la productividad y favorecer la conciliación de la vida laboral y personal, respetando en todo caso los mínimos legales en materia de descansos diarios, semanales y anuales.»

(85) La mayor representatividad se mide de conformidad con los criterios tasados de los arts. 6 y 7 de la Ley Orgánica 11/1985, de 2 de agosto, de Libertad Sindical.

(86) La cursiva es nuestra.

(87) Resolución de 15 de junio de 2015, de la Dirección General de Empleo, por la que se registra y publica el III Acuerdo para el Empleo y la Negociación Colectiva 2015, 2016 y 2017. BOE 20 junio 2015. 
Si bien es verdad que el ANC prevé cláusulas generales sobre horarios de trabajo, también lo es que exige que se combinen los objetivos de la mejora de la productividad y la conciliación, eso sí, con especial respeto hacia los «descansos diarios, semanales y anuales». Por tanto, en cuanto que las Administraciones Públicas no se rigen sólo por la productividad, ni, premisa anterior a lo expuesto, este ANC puede proyectarse a los funcionarios/as, se puede concluir que las excepciones relativas al descanso del personal de los servicios de protección civil no pueden establecerse en sede de un acuerdo celebrado entre una entidad local y su personal, por ejemplo. Sí, en cambio, en sede legal, como se ha demostrado que ha ocurrido con las Leyes de Ordenación Sanitaria de Euskadi y de la Policía Vasca (leyes 8/1997 y 4/1992, respectivamente).

En definitiva, pues, un acuerdo del EBEP como cualquiera de los traídos a colación en este trabajo, por razón de su ámbito de aplicación o, mejor dicho, de su unidad de negociación, no sería el apropiado para regular este tipo de excepciones a la regulación establecida en la Directiva (art. 17.3, a sensu contrario).

\section{Conclusiones}

La legislación propiamente administrativa, tanto del Estado como, con matizaciones, de esta Comunidad Autónoma, rehúye determinar tanto la duración diaria de la jornada como la limitación de la misma por medio del descanso diario en relación con el funcionariado, en general y con el personal de protección civil analizado, en particular. Con todo, las pocas referencias al tiempo de trabajo encontradas en esa legislación tanto general como específica se refieren a la «jornada de trabajo». Según el Diccionario de la Real Academia de la Lengua, el término "jornada» responde al "tiempo de duración del trabajo diario".

El Acuerdo regulador del Servicio de Bomberos de la Diputación de Gipuzkoa, el más polémico de los estudiados, sustituye «jornada» por "turnos de 24 horas", estableciendo módulos de 24 horas que no se realizaban ni en las épocas más oscuras de los prolegómenos del capitalismo (88), contraviniendo de este modo una regulación directamente aplicable a este servicio: la Directiva 2003/88/CE; aunque no suponga una vulneración del principio de jerarquía con fundamento jurídico en las disposiciones de la Directiva relativas al descanso - por combinación de

(88) GOERLICH PESET, J.M.: «Tiempo de trabajo y negociación colectiva», en CCNCC (coord. GOERLICH PESET): El tiempo de trabajo en la negociación colectiva, Ed. Ministerio de Trabajo e Inmigración, Madrid, 2008, p. 17 quien declara que «sólo a su través [limitar la jornada de trabajo] es posible defenderla frente a la extenuación propia de los sistemas anteriores de explotación de la mano de obra". 
esos artículos con las excepciones permitidas por el art. 17-, cuanto por que interviene el trabajo nocturno en el desempeño de las actividades de protección civil analizadas en eta sede.

También la Constitución Española exige que se garantice el descanso necesario mediante la limitación de la jornada laboral, o diaria, norma que debería aplicarse y no sustituirse por el módulo "de 24 horas", que, como es fácil de entender, representa una jornada diaria sin ninguna limitación, y que impide hacer otra cosa que trabajar durante 24 horas ininterrumpidas; o, en el caso analizado del personal de bomberos, mínimamente interrumpidas por reducidos asuetos dedicados a la manutención. Es cierto que ese mandato constitucional es un principio de la política social y económica que requiere desarrollo legal para poder ser alegable (art. 53.3 CE) y que no ha sido transpuesto en materia de tiempo de trabajo del funcionariado, menos al del Servicio de Bomberos. Sin embargo, conforme a ese artículo constitucional quedarían prohibidas las jornadas de 24 horas consecutivas, por constituir una vulneración de la exigencia de la "limitación de la jornada" que predica el art. 40.2 CE, aunque, de nuevo hay que insistir en que no se ha desarrollado legislativamente en el ámbito del sector público.

El Estatuto de los Trabajadores, aun no siendo de aplicación a los funcionarios/as, establece en su artículo 34 el límite máximo de duración de la jornada laboral, sin perjuicio de la realización de horas extraordinarias (art. 35 ET). Aunque esta ley (y el RJE) no es proyectable a los funcionarios/as, ante la ausencia de normativa específica, debería servir de referencia en estos casos (89) ya que la limitación del tiempo de trabajo es un elemento clave de la prevención de riesgos laborales. Y si la Ley 31/1995, de 8 de noviembre, de Prevención de Riesgos Laborales es norma básica para el personal funcionario y estatutario y se aplica a las Administraciones Públicas en los términos de su Disposición Adicional 3. ${ }^{a}$, este otro aspecto de la política de prevención - esto es la limitación de la jornadadebería ser también tomado en consideración.

Por su parte, tal como se ha insistido más atrás, la Directiva 2003/88/ CE, aplicable también al personal empleado de la Función Pública, prevé en su artículo 3 que "Los Estados miembros adoptarán las medidas necesarias para que todos los trabajadores disfruten de un período mínimo de descanso diario de 11 horas consecutivas en el curso de cada período de 24 horas"; reiteración del descanso diario que corrobora el art. 5 de la norma comunitaria, avalada por la sentencia JAEGER del TJUE (90).

(89) Y se ha comprobado que sirve de canon para la Ertzaintza.

(90) Apartados 95 y 96. 
No obstante, tampoco hay que olvidar que el apdo. $3 .^{\circ}$ del art. 17 de la Directiva 2003/88/CE prevé posibles excepciones relativas al descanso entre jornadas por la necesidad de garantizar la continuidad del servicio o de la producción, entre las que se encuentra la actividad de los médicos en urgencias, la policía vasca y los bomberos/as. Es obvio que la legislación española no ha "aprovechado" - si se quiere ver así - la posibilidad brindada por la Directiva 2003/88/CE de exceptuar algunos servicios de la protección civil de la legislación general en materia de jornada máxima y descanso diario; a lo que puede añadírsele que es materia que se ha brindado a la negociación colectiva. De ahí que no pueda entenderse que existe un incumplimiento por parte del Reino de España de esta concreta previsión de la Directiva.

Ahora respecto de los trabajadores nocturnos - sirviéndonos de la descripción que realiza de ellos la propia Directiva de 2003 y la legislación laboral-, condición que sin duda reúne el personal bombero, se ha concluido que el número máximo de horas diarias (8) que realiza este personal no puede ser superado por un Acuerdo de la naturaleza del analizado en este trabajo; y en él se contienen módulos de 24 horas seguidas de tiempo de trabajo ordinario. Y ello, especialmente, es debido al delicado trabajo que prestan esas personas, que requiere unas condiciones físicas y psíquicas que difícilmente pueden reunirse tras 22 horas de trabajo, por ejemplo; y varias veces a la semana, siguiendo con en caso de los bomberos. Esta respuesta jurídica se concilia bien con lo dispuesto en otros textos internacionales, como el Convenio n. 19 de la OIT, organización cuyos principios relativos al descanso y su respeto también menciona el Preámbulo de la Directiva de 2003 (apdo. 6).

En definitiva, en el Servicio de Bomberos de Gipuzkoa habría de aplicarse un descanso mínimo entre jornadas; reposo diario que es prescriptivo tanto desde la vertiente del descanso ininterrumpido de once horas en cada período de 24 (art. 3 Directiva), - preferiblemente en horario nocturno por ser el más idóneo y por alinearse con los hábitos y costumbres sociales (91)-, como desde la vertiente de la duración de la jornada, esto es, por el límite de ocho horas diarias de trabajo efectivo en el caso de trabajadores/as nocturnos, principalmente por la especial prestancia física y psíquica que se exige al personal bombero, por sí mismo y para desempeñar correctamente su trabajo. Si no se hiciera, el descanso diario perdería el efecto directo que tiene atribuido, el de impedir concentraciones excesivas en la jornada diaria, pero también se desaprovecharía su efecto indirecto: garantizar un mínimo de días labo-

(91) LÓPEZ AHUMADA, J.E.: “Descansos semanales...», op. cit., p. 43 
rales en los cuales se debe repartir la jornada (92); y de paso, una posible excepción de la regla del descanso diario los neutralizaría tanto que la aplicación de la Directiva no podría combatir el efecto pernicioso que tienen "módulos" tan largos. El descanso diario no sólo se conforma por un "quantum» de tiempo para el reposo libre de disponibilidad del servicio o empresa, sino también por el "cuando" de su disfrute. Y en el caso que nos entretiene, la configuración del segundo elemento no es adecuada (93).

En resumen, a pesar de la falta de desarrollo normativo-administrativo del art. $40 \mathrm{CE}$, tanto por salud, como por la tendencia hacia la «unitarización" de las condiciones laborales; pero también por lo dispuesto en la legislación laboral que actúa de referente, $y$, en fin, por encontrarnos ante un poder público vinculado y sometido a las leyes, con la Directiva citada y la jurisprudencia del TJUE como referencia simpar, se concluye que ni por la naturaleza del acuerdo colectivo analizado, ni, obviamente, por acuerdo individual es pertinente anular ordinariamente el descanso diario entre jornadas del personal de protección civil. Lo que no ocurre en el ámbito de Osakidetza, ni en la Ertzaintza por cuanto la normativa legal y convencional vinculan esas excepciones a circunstancias especiales y por que sus trabajadores no se inscriben en el concepto de trabajador nocturno; ni se someten a sus limitaciones.

Todo lo anterior sin adentrarnos en los inconvenientes que un horario así puede tener en la conciliación de la vida laboral, familiar y personal; y estando alineados con la reflexión de que los convenios colectivos deben convertirse en un instrumento de sensibilización e implantación real de la igualdad y con que "la negociación colectiva en el ámbito del empleo público asume el reto de proporcionar un cambio de enfoque tendente a incentivar la corresponsabilidad entre mujeres y hombres» (94).

Cierto tiempo de trabajo analizado en este trabajo pierde su función de protección de la salud de los trabajadores/as - bomberos, señaladamente hombres en el caso que nos ocupa, salvo alguna excepción-, ciñéndose a la labor de determinación del trabajo debido(95). Como bien se ha expresado "El descanso entre jornadas sería el descanso que, con más vigor, ha resistido los procesos de flexibilización del sistema de

(92) EZQUERRA ESCUDERO, L.: Tiempo de trabajo.., op. cit., p. 244.

(93) EZQUERRA ESCUDERO, L.: Tiempo de trabajo.., op. cit., p. 247. La STJUE 9 de septiembre de 2003 (TJCE 2003/250) declaró que «con objeto de garantizar una protección eficaz de la seguridad y de la salud del trabajador debe preverse, en general, una alternancia regular entre un período de trabajo y un período de descanso". La cursiva es nuestra.

(94) GARCÍA TORRES, A.: Ordenación del tiempo de trabajo, igualdad y corresponsabilidad en las Administraciones Públicas. CES, 2010, pp. 14 (prólogo) y 5.

(95) Así, MERINO SENOVILLA, A.: «La jornada de trabajo», op. cit., p. 274. 
tiempo de trabajo" situándonos "ante un límite intrínseco a la delimitación de la jornada laboral» (96), límite que las partes de un Acuerdo como el examinado no pueden traspasar.

En definitiva, el Acuerdo del personal bombero estudiado se opone a la Directiva, y a las disposiciones que permiten excepcionar parte de su articulado, por dos razones de peso: (i) esas 24 horas incluyen trabajo nocturno y lo incluyen de modo "ordinario" y (ii) el Acuerdo analizado no alcanza la naturaleza del tipo de pactos o acuerdos que podrían contener las excepciones que contempla. Excepciones que, de existir, tampoco podrían separarse tanto de los cánones de la directiva como para desnaturalizar su efecto útil.

Para finalizar, es un lugar común en la jurisprudencia de la Unión Europea como en la doctrina científica que las directivas pueden ser «selfexecuting" (o tener un efecto directo) cuando su contenido es lo suficientemente claro para poder prescindir del desarrollo por parte del aparato legislativo estatal (97); y el texto de la Directiva de 2003 que manejamos y su jurisprudencia, lo son sin duda alguna. Así se manifestó la jurisprudencia del Tribunal de Justicia de la Unión Europea (sentencia de 5 de octubre de 2004, Caso "Pfeiffer») (98). Si desde el punto de vista de su contenido, una Directiva no está sujeta a condición alguna y es suficientemente precisa, los particulares están legitimados para invocarla ante los órganos jurisdiccionales nacionales contra el Estado en dos supuestos: cuando el Estado no adopte el Derecho nacional a la Directiva dentro de los plazos señalados, bien cuando haya una inadaptación incorrecta o no se transponga. Por eso, la propia Directiva 2003/88/ CE advierte de que reclamar su aplicación no puede servir de causa o excusa para disminuir el nivel general de protección de los trabajadores en sentido laxo. Así de taxativo es el texto del art. 23 de la Directiva de 2003: "Sin perjuicio del derecho de los Estados miembros de adoptar, habida cuenta de la evolución de la situación, disposiciones legales, reglamentarias y contractuales distintas en materia de tiempo de trabajo, siempre que se cumplan los requisitos mínimos establecidos en la presente Directiva, la aplicación de la presente Directiva no constituirá una justificación válida para la disminución del nivel general de protección de los trabajadores».

(96) LÓPEZ AHUMADA, J.E.: «Descansos semanales...», op. cit., p. 37 . En la nota $\mathrm{n} .{ }^{\circ} 28$ el autor relata los avatares parlamentarios que exitosamente afrontó este precepto durante su tramitación parlamentaria.

(97) MARTINES, F.: "Direct effect of international agreements of the European Union», European journal of international law», Journal europeen de droit international, Vol. 25, n. ${ }^{\circ} 1,2014$, págs. 129-147.

(98) Asuntos C-397/01 y C-403-01. 
Y si los Estados miembros tienen prohibido establecer una duración de la jornada de los trabajadores nocturnos por encima del límite de las ocho horas en períodos de referencia de 24 horas en circunstancias normales, menos justificación tendría que el personal de protección civil lo reclame al albur de otros intereses.

Trabajo recibido el 13 de diciembre de 2016

Aceptado por el Consejo de Redacción el 26 de mayo de 2017 
LABURPENA: Babes zibilean zerbitzu ematen duten enplegatu publiko batzuei ezar dakiekeen lan-denboraren araubide juridikoaren azterketa jasotzen du ikerketa honek. Era berean, ohiko erregulazioa eta zuzentarau europarrak aztertuko dira. Zerbitzu publiko egokia eskaintzeko betebeharrak, batzuetan, ez du bat egiten atsedenerako eskubidearekin, eta horrek lotura zuzena du pertsonen osasunarekin. Ikerketa honen lehentasunezko xedea izango da, bestalde, lanaldiaren eta atsedenaren gutxieneko arauak zeintzuk diren ikustea eta horien gainean negoziatzeko legitimatuta dauden subjektuek arauak aldatzeko aukera edukitzea.

GAKO HITZAK: Babes zibila. Lanaldia. Atsedenaldia. Gaueko lana. Negoziazio kolektiboa.

RESUMEN: El presente estudio se enfoca al análisis del régimen jurídico del tiempo de trabajo aplicable a ciertos empleados públicos que prestan servicios de protección civil. La regulación convencional y las directivas europeas serán también objeto de análisis. La obligación de ofrecer un adecuado servicio público puede, en ocasiones, enfrentarse al derecho al descanso, indefectiblemente unido a la salud de las personas. Averiguar cuáles son las normas mínimas de jornada y descanso, como la posibilidad de ser modificadas por parte de los sujetos legitimados para negociar, será otro de los objetivos prioritarios de este estudio.

PALABRAS CLAVE: Protección civil. Jornada. Descanso. Trabajo nocturno. Negociación colectiva.

ABSTRACT: This study focuses on the analysis of the legal regime of the working time applicable to some civil servants that provide civil protection services. The conventional regulation and the European directives will also be analyzed. The obligation to provide with an adequate public service sometimes can run against the right to rest, necessarily linked to people's health. Another priority objective in this work is to find out the minimum rules on working day and rest together with the options to amend them by the individuals legitimated to negotiate.

KEYWORDS: Civil protection. Work hours. Night work. Collective bargaining. 